Manuscript received January 13 2017; accepted for publication November 1, 2017; published online May 16, 2018.

1 Division of Exploration and Production Technology, Repsol Technology Center, Agustín de Betancourt s/n, Móstoles 28935, Madrid, Spain

${ }^{2}$ Department of Civil and Environmental Engineering, Division of Geotechnical Engineering and Geosciences, Technical University of Catalonia (UPC-Barcelona Tech), Rm. D2-202b, Building D2, Jordi Girona 1-3, 08034 Barcelona, Spain (Corresponding author), e-mail: pere.prat@upc.edu, (1) https://orcid.org/0000-00022177-1758

${ }^{3}$ Department of Civil and Environmental Engineering, Division of Geotechnical Engineering and Geosciences, Technical University of Catalonia (UPC-Barcelona Tech), Rm. D2-209, Building D2, Jordi Girona 1-3, 08034 Barcelona, Spain
M. R. Lakshmikantha, ${ }^{1}$ Pere C. Prat, ${ }^{2}$ and Alberto Ledesma ${ }^{3}$

\section{Boundary Effects in the Desiccation of Soil Layers with Controlled Environmental Conditions}

\section{Reference}

Lakshmikantha, M. R., Prat, P. C., and Ledesma, A., "Boundary Effects in the Desiccation of Soil Layers with Controlled Environmental Conditions," Geotechnical Testing Journal, Vol. 41, No. 4, 2018, pp. 675-697, https:// doi.org/10.1520/GTJ20170018. ISSN 0149-6115

\section{ABSTRACT}

This article presents the results of an experimental research carried to investigate the mechanics of cracking of soil layers under drying conditions. The tests were conducted under controlled laboratory conditions and in an environmental chamber with circular and rectangular specimens to investigate the effect of the boundary conditions (size, shape, and aspect ratio of the specimens and containers) on the process of initiation and propagation of cracks and on the final crack pattern at the end of desiccation. The tests in the environmental chamber were conducted with imposed temperature and relative humidity and provided new insight into the mechanics of the formation of cracks in a drying soil, and they showed that cracks can initiate either at the top, bottom, or at both surfaces of the drying specimen. The results also reveal how the crack patterns are controlled by the existing mechanical and hydraulic boundary conditions. The cracks seem to form sequentially in patterns that can be explained by three key factors: stresses higher than the tensile strength, the direction of the generated stresses, and the stress redistribution in the vicinity or inside the newly formed domain. In order to substantiate the sequential nature of the crack pattern formation, experimental evidences showing the existence of a cracking sequence during the laboratory desiccation experiments are presented and analyzed.

\section{Keywords}

desiccation cracks, boundary conditions, sequential cracking, environmental chamber, unsaturated soils

\section{Introduction}

Cracks develop in soils as a result of environmental oscillations, changes in temperature, air relative humidity, solar radiation, wind, etc., that alter the water content and form complex random patterns that are further controlled by the existing or imposed physical (mechanical or hydraulic or both) boundary conditions. Although cracking is often attributed to drying resulting from water loss, mostly through evaporation, there is evidence that soils also crack during wetting episodes following previous desiccation cracking (Cordero et al. 2014; Cordero et al. 2015; Levatti 2015). Examples can be found in irrigated land, 
tailing ponds for mining waste, landfill liners, earth embankments, reclaimed land, reservoir beds, etc. where cracks seem to form naturally following a sequential pattern: a single crack or several cracks can form simultaneously in the initial stages of drying, and, as they propagate, several additional secondary cracks are formed. Then, tertiary cracks may form in the same manner, and so on.

The presence of cracks strongly affects the mechanical and hydraulic properties of the soil mass. In order to study this phenomenon, experimental investigation has been carried with different purposes and in different scientific and technological fields (surface and underground hydrology, edaphology, agronomy, meteorology, physics, civil and geotechnical engineering, etc.) since the middle of last century (Asahina et al. 2014; Ávila 2004; Ayad, Konrad, and Soulié 1997; Chertkov 2002; Chertkov and Ravina 1999; Corte and Higashi 1960; Goehring et al. 2015; Kodikara, Barbour, and Fredlund 2000; Lakshmikantha 2009; Lakshmikantha, Prat, and Ledesma 2009, 2012; Levatti et al. 2017; Lloret et al. 1998; Miller 1975; Morris, Graham, and Williams 1992; Nahlawi and Kodikara 2006; Péron 2008; Péron et al. 2009; Rodríguez et al. 2007; Sánchez, Manzoli, and Guimarães 2014; Tang et al. 2011). Many of the earlier studies focused mostly on the mechanics of the phenomenon, rather than on the morphology of cracks and the practical implications of cracked soils. These experiments dealt primarily with the effects of the thickness of the drying soil on parameters such as cracking moisture content, desiccation rate, desiccation coefficient, crack width and spacing, etc., without looking deeper into the effects of the specimen's shape, size, or boundary conditions, and without proper environmental control and instrumentation. However, boundary conditions, coupled with the shape and size of the specimen, play an important role in the development of cracking, and this is especially important when the laboratory results need to be extrapolated to field conditions that are of several orders of magnitude larger.

This article describes the results of laboratory experiments devised to illustrate the effect of boundary conditions on the cracking process in two types of environment: open-air in a controlled laboratory environment and in an environmental chamber where temperature and relative humidity can be imposed on the specimens. Four series of tests were conducted; Series 1-3 were conducted in the open-air laboratory setting, and Series 4 was conducted in the environmental chamber. Series 1 consisted of circular specimens of thicknesses 4,8 , and $16 \mathrm{~mm}$, with three different bottom contact surfaces. Series 2 was carried out with rectangular containers of different sizes, aspect ratios, and thicknesses (10 and $15 \mathrm{~mm}$ ). Series 3 was also carried with rectangular specimens but of the same aspect ratio and different sizes and thicknesses (10 and $20 \mathrm{~mm}$ ). Series 4 consisted of circular specimens of 40 and $80 \mathrm{~cm}$ in diameter and different bottom contact surfaces. The results of the experiments show the effect of the drying surface area and the thickness on the desiccation rate and desiccation coefficient, as well as the effect of size and boundary conditions on the crack formation and on the type of crack patterns that develop during the tests.

\section{The Environmental Chamber}

The environmental chamber used in the investigation was designed to study cracking in soils as a result of drying or wetting conditions by imposing and controlling environmental conditions and eventually studying the impact of cycles of such environmental conditions (Lakshmikantha 2009). The equipment is capable of monitoring the changes of the porewater pressure within the soil specimen while the moisture changes as well as taking photographic images of the top surface of the specimen (Cordero et al. 2014; Cordero et al. 2015; Levatti et al. 2017).

Fig. 1 shows the chamber with its main components in its laboratory position. The walls and cover of the chamber are made of 1-cm-thick poly(methyl methacrylate) with dimensions of $1 \mathrm{~m}$ by $1 \mathrm{~m}$ by $1.5 \mathrm{~m}$, which are sustained by a much thicker polyvinyl chloride (PVC) base plate with a specially designed rubber tube to guarantee airtightness. The body of the chamber has four circular openings of about 100-mm diameter to allow entry and exit of dry or humid air from the chamber to the humidifier and dehumidifier. Two more airtight utility openings are available for minor adjustments during the experiments. PVC containers with a grooved bottom surface and different diameter depths (80-20, $80-10,40-10$, and $20-5$, dimensions in $\mathrm{cm}$ ) were specially

FIG. 1 View of the environmental chamber.

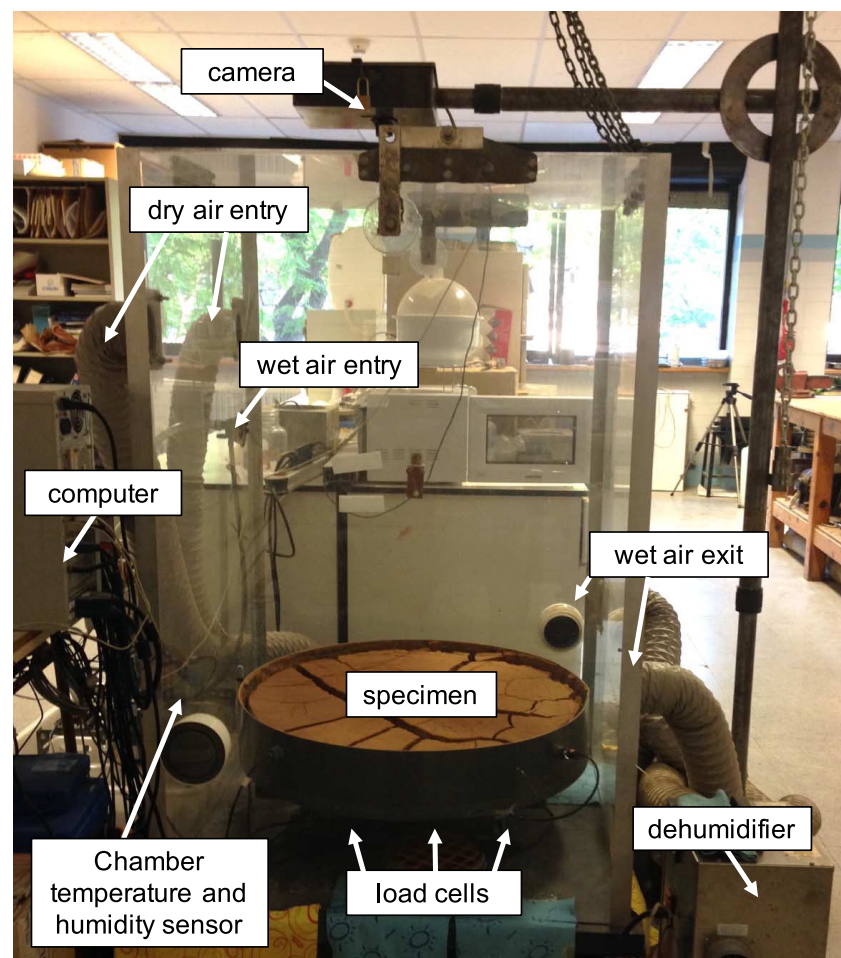


designed to house the sensors at strategically important locations. An additional container with a smooth bottom surface (80-10-P) is also available.

The further equipment required to operate the chamber includes a digital camera to capture images automatically at prescribed time frequencies and a sensor to monitor the air temperature and relative humidity inside the chamber. All the equipment and sensors are connected to a computer-controlled data acquisition system with a custom-build software. This allows experiments with suction and temperature control by imposing different air temperatures and relative humidity inside the chamber.

\section{SENSORS AND LOAD CELLS}

Suction changes are measured with UMS-T5 tensiometers (UMS $\mathrm{GmbH}$, Frankfort, Germany) that are of a small size and are accurate at very low suctions, with a working range of $+100 \mathrm{kPa}$ to $-85 \mathrm{kPa}$. Fig. 2 shows the location of the tensiometers in the container. Four tensiometers were placed on the bottom surface, one at the center (T1) and three others (T2-T4) at midpoints between the center and the wall, spaced $120^{\circ}$. Two additional tensiometers (T5 and T6) were placed on the wall of the container (Ø80 specimens only) to record suctions during the early stages of desiccation. The tensiometers are placed at different depths in order to gain detailed information of the suction distribution with depth.

Two Vaisala HMP-230 sensors (Vaisala, Vantaa, Finland) are used to monitor the changes in porewater pressure and temperature within the soil specimen (sensors V1 and V2 in Fig. 2). An additional Vaisala HMD/W70 sensor (Vaisala, Vantaa, Finland),

FIG. 2 Plan view and cross section showing the location of tensiometers (T1-T6) and Vaisala temperature and humidity sensors (V1 and V2).
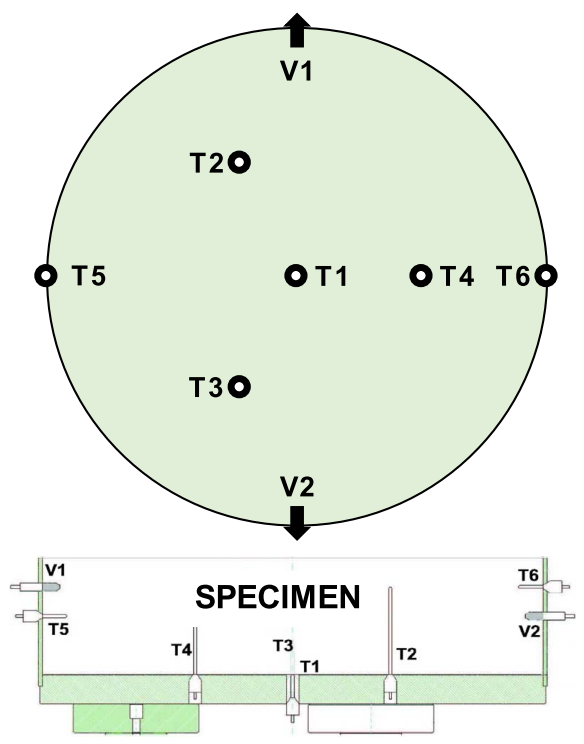

mounted on the interior face of the chamber wall (Fig. 1), is used to measure the air temperature and relative air humidity.

Three INTERFACE SSM series load cells (Interface, Inc., Atlanta, Georgia) are used to monitor the variation of weight that is due to water evaporation or wetting during the tests. The load cells are located under the base plate in an equilateral triangular pattern and are sandwiched between the isolators and support plates.

\section{IMAGE ACQUISITION}

An Olympus C-5050Z camera (Olympus Corporation, Tokyo, Japan) is used to record images of the process of formation and propagation of cracks. The camera is fully computercontrolled and takes pictures automatically at a prescribed time frequency. To support and position the digital camera, a specialpurpose mechanical arm was designed and constructed in the shape of an inverted letter " $L$ " that consists of a vertical extensible column supporting a horizontal cantilever arm that can be adjusted to properly position the camera so as to get undistorted top views of the specimen during the test.

\section{TEMPERATURE AND RELATIVE HUMIDITY CONTROL EQUIPMENT}

To impose the desired temperature and humidity, a heating source and a dehumidifier are installed in the chamber. The heat source are two infrared lamps which turn on and off according to the prescribed temperature by means of a computer-controlled interface. The air moisture is removed by means of a DST-Seibu Giken RECUSORB DR-010B commercial dehumidifier (DST-Seibu Giken, Spanga, Sweden) that is connected in a closed circuit with the environmental chamber recycling the air. The air entering and exiting the dehumidifier has approximately the same temperature so that the heating system does not have to work harder to compensate for the heat loss during the dehumidifying process.

\section{SOFTWARE INTERFACE}

A software interface was specially programmed to control the tests in the environmental chamber, also allowing for the calibration curves of the sensors. Data acquisition intervals can be set from one second to several days. The software has also an interface for prescribing the temperature and relative humidity of the environmental chamber.

Two National Instruments Data Acquisition Cards (Peripheral Component Interconnect [PCI] Card, NI-PCI:6023, National Instruments, Austin, TX) were used for data acquisition. The PCI cards were mounted in the computer's central processing unit with a separate connection box made to connect all the analogical inputs from the sensors to the different channels of the data acquisition card. The connection box also has digital outputs for controlling the heating and dehumidifier equipment and houses the necessary signal amplifiers and conditioners and electrical installation to power the sensors. 
Image acquisition was performed using CAM2COM (Sabsik and Sergei Menchenin), a software that can control all of a camera's operations, including prescribing times for taking pictures, setting frequency-intervals, selecting output devices for storing images, etc.

\section{Experimental Program}

The soil used in the experiments is a Barcelona silty clay. This type of soil is commonly found in the region and has been extensively studied in the past in the laboratory (Barrera 2002). It is a finegrained soil with $60 \%$ passing the \#200 sieve. Its main parameters are as follows: unit weight of soil particles $\gamma_{s}=27 \mathrm{kN} / \mathrm{m}^{3}$; liquid limit $w_{L}=32 \%$; and plastic limit $w_{P}=16 \%$. According to the unified soil classification system, the soil can be classified as low plasticity clay.

To prepare the specimens, the soil was allowed to dry in open air and was then passed through a $2-\mathrm{mm}$ mechanical sieve. The dry material that passed through was then mixed with distilled water until a visibly homogeneous paste was obtained; this was then poured into the containers for testing. The mix proportions between the dry material and water were fixed to make the moisture contents of all specimens at the time of fabrication equal to their liquid limit. This value is not the same as the moisture content of the specimen at the beginning of the test; the difference is due to the water evaporation that occurred during the time that passed between fabrication and test initiation and specimen manipulation. The actual initial moisture content is indicated in the following paragraphs for each series of tests and was determined from a small specimen taken from each specimen at the initiation of the test.

The specimens of the first series were circular with a diameter of $22.5 \mathrm{~cm}$ (see Fig. 3 and Table 1) and were of three different thicknesses - 4, 8, and $16 \mathrm{~mm}$. Additionally, a set of tests with specimens of equal thicknesses $(8 \mathrm{~mm})$ were performed with three different types of bottom contact surfaces between the soil specimen and the container-smooth, with circular grooves, and with a square grid pattern (see Fig. 4). This series extended previous research conducted with the same type of circular specimen (Lloret et al. 1998; Rodríguez 2006) to include crack pattern analysis.

The second series of tests was carried out with rectangular specimens of different sizes, aspect ratios, and thicknesses. Test \#1 is a sequence of five geometrically similar 10 -mm-thick specimens with aspect ratios of approximately 1.5 and increasing surface areas ranging from $350 \mathrm{~cm}^{2}$ to $1,450 \mathrm{~cm}^{2}$. Tests $\# 2-7$ were carried out on three specimens, each with different geometric parameters. Specimens for Tests \#2 and \#3 had thicknesses of $10 \mathrm{~mm}$, whereas specimens for Tests \#4-7 had thicknesses of $15 \mathrm{~mm}$. The complete geometric characteristics of the specimens for each test are given in Table 2. Because the available laboratory containers were not all equal, the specimens had different cross sections (trapezoidal in Test \#1, square in Tests \#2 and \#3, and

FIG. 3

Final crack pattern of circular specimens with circular grooved bottom and different thickness: (a) $4 \mathrm{~mm}$, (b) $8 \mathrm{~mm}$, and (c) $16 \mathrm{~mm}$.

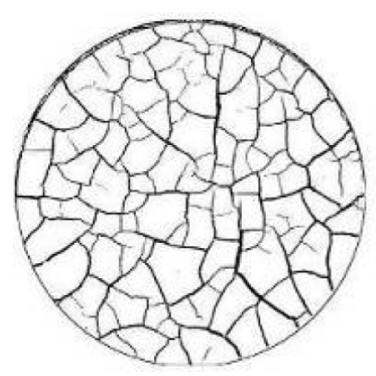

(a) $h=4 \mathrm{~mm}$

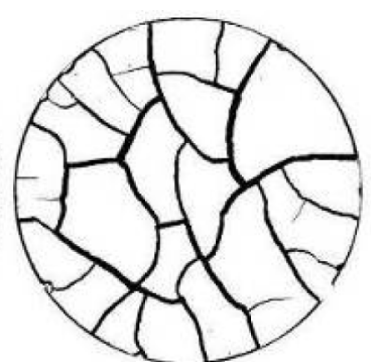

(b) $h=8 \mathrm{~mm}$

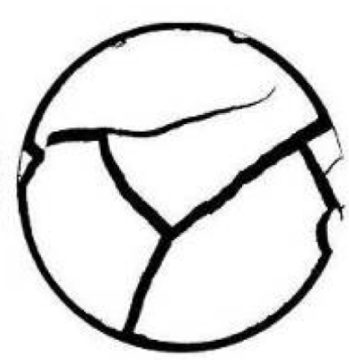

(c) $h=16 \mathrm{~mm}$

TABLE 1 Geometry and results from tests with circular specimens_first series.

\begin{tabular}{|c|c|c|c|c|c|c|c|}
\hline Test & Thickness, mm & Area, $\mathrm{cm}^{2}$ & Number of Cells & $\begin{array}{l}\text { Average Area } \\
\text { of Cells, } \mathrm{cm}^{2}\end{array}$ & $\begin{array}{l}\text { Average Width } \\
\text { of Cracks, mm }\end{array}$ & $\begin{array}{l}\text { Length of Cracks } \\
\text { per Unit Area, } \mathrm{cm}^{-1}\end{array}$ & $C D F^{\mathrm{a}},(\%)$ \\
\hline $\mathrm{C}-4$ & 4 & 398 & 98 & 3.58 & 0.112 & 1.05 & 11.73 \\
\hline C-8 & 8 & 398 & 21 & 15.31 & 0.250 & 0.55 & 19.16 \\
\hline C-16 & 16 & 398 & 6 & 53.20 & 0.460 & 0.32 & 19.75 \\
\hline C-Plain & 8 & 398 & 25 & 12.64 & 0.370 & 0.56 & 20.58 \\
\hline C-Circular & 8 & 398 & 19 & 17.82 & 0.385 & 0.52 & 19.92 \\
\hline C-Grid & 8 & 398 & 12 & 25.62 & 0.440 & 0.46 & 20.21 \\
\hline
\end{tabular}

Note: ${ }^{\text {a } C r a c k ~ D e n s i t y ~ F a c t o r . ~}$ 
FIG. 4

Schematic diagram of different contact surfaces and the final crack pattern with 8-mm-thick circular specimens (not to scale).
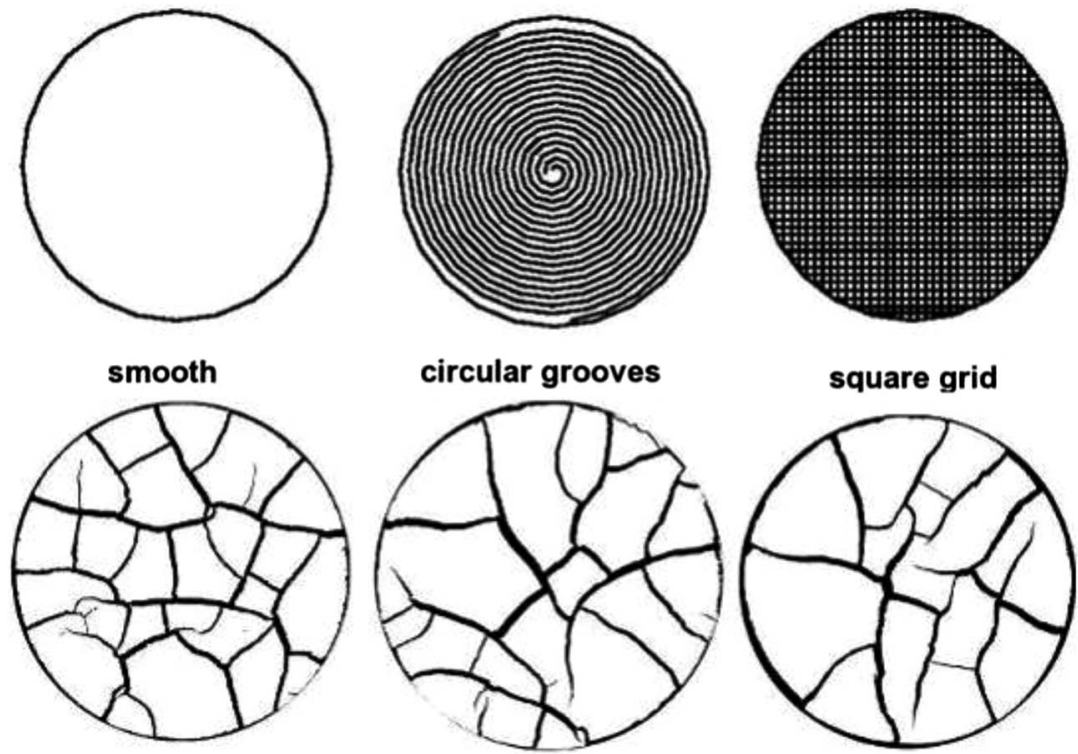

TABLE 2 Geometry and results from tests with rectangular specimens of different geometries-second series (Tests 1 to 7 )

\begin{tabular}{|c|c|c|c|c|c|c|c|c|}
\hline Test & Thickness, mm & Aspect Ratio & Area, $\mathrm{cm}^{2}$ & Number of Cells & $\begin{array}{l}\text { Average Area } \\
\text { of Cells, } \mathrm{cm}^{2}\end{array}$ & $\begin{array}{l}\text { Average Width } \\
\text { of Cracks, mm }\end{array}$ & $\begin{array}{c}\text { Length of Cracks } \\
\text { per Unit Area, } \mathrm{cm}^{-1}\end{array}$ & $C D F^{\mathrm{a}}, \%$ \\
\hline $1 \mathrm{a}$ & 10 & 1.5 & 352 & 48 & 6.7 & 1.06 & 0.762 & 8.1 \\
\hline $1 \mathrm{c}$ & 10 & 1.5 & 726 & 66 & 10.1 & 1.28 & 0.674 & 8.6 \\
\hline $1 \mathrm{~d}$ & 10 & 1.5 & 999 & 126 & 7.3 & 0.95 & 0.871 & 8.2 \\
\hline 3 & 10 & 2.0 & 200 & 30 & 6.0 & 1.20 & 0.753 & 9.0 \\
\hline 4 & 15 & 2.0 & 91 & 12 & 6.9 & 1.94 & 0.646 & 12.4 \\
\hline 5 & 15 & 4.5 & 188 & 15 & 11.9 & 2.06 & 0.633 & 13.0 \\
\hline 6 & 15 & 1.5 & 301 & 10 & 26.5 & 4.26 & 0.352 & 14.4 \\
\hline 7 & 15 & 2.0 & 511 & 21 & 20.5 & 3.43 & 0.415 & 14.2 \\
\hline
\end{tabular}

Note: For tests $2-7$, the values given are the average values of the three specimens tested.

${ }^{\mathrm{a}}$ Crack Density Factor.

rounded bottom edges in Tests \#4-7). The analysis conducted after the completion of the tests showed that this variability introduced additional factors affecting the mechanisms of cracking, indicating that laboratory experiments are greatly influenced by the boundary conditions and, thus, led the way to larger-scale experiments (third series) where the variable's aspect ratio and the container's edge type were removed, thereby permitting the study of more fundamental variables.

The specimens of the third series consisted of five geometrically similar rectangles with an aspect ratio of $\sqrt{2}$ and surface areas of $1,0.5,0.25,0.125$, and $0.0625 \mathrm{~m}^{2}$ (Table 3) in two subseries of different thickness (10 and $20 \mathrm{~mm}$ ). The containers were made of PVC, and, because of their larger size, they were glued to a wooden base coated with water-resistant paint to provide the necessary stiffness for handling and placement over the load cells.

Series 4 consisted of three tests with $10-\mathrm{cm}$-thick circular specimens. One of the specimens had a diameter of $40 \mathrm{~cm}$ and a grooved bottom surface. The other two specimens had a diameter of $80 \mathrm{~cm}$, one of them with a smooth bottom surface and the other with a grooved bottom surface. The complete geometric characteristics of the specimens for each test are given in Table 4.

In Series 1 and 2, the specimens were initially weighed to an accuracy of $0.01 \mathrm{~g}$ and placed on a level surface in the environment-controlled laboratory $\left(T=21 \pm 0.5^{\circ} \mathrm{C}, R H=52 \pm 2 \%\right)$. 
TABLE 3 Geometry and results from tests with rectangular specimens of similar geometry-third series (Tests AO to A4).

\begin{tabular}{|c|c|c|c|c|c|c|c|c|}
\hline Test & Thickness, mm & Aspect Ratio & Area, $\mathrm{cm}^{2}$ & Number of Cells & $\begin{array}{l}\text { Average Area } \\
\text { of Cells, } \mathrm{cm}^{2}\end{array}$ & $\begin{array}{l}\text { Average Width } \\
\text { of Cracks, mm }\end{array}$ & $\begin{array}{c}\text { Length of Cracks } \\
\text { per Unit Area, } \mathrm{cm}^{-1}\end{array}$ & $C D F^{\mathrm{a}}, \%$ \\
\hline A0-10 & 10 & 1.41 & 10,000 & 1,272 & 6.94 & 1.61 & 0.73 & 11.71 \\
\hline A $1-10$ & 10 & 1.41 & 5,000 & 466 & 9.57 & 1.95 & 0.55 & 10.79 \\
\hline A2-10 & 10 & 1.41 & 2,500 & 219 & 10.08 & 1.96 & 0.58 & 11.67 \\
\hline A3-10 & 10 & 1.41 & 1,250 & 95 & 11.96 & 1.99 & 0.45 & 9.12 \\
\hline A4-10 & 10 & 1.41 & 625 & 34 & 16.98 & 2.00 & 0.37 & 7.64 \\
\hline A0-20 & 20 & 1.41 & 10,000 & 249 & 35.55 & 4.11 & 0.28 & 11.49 \\
\hline A $1-20$ & 20 & 1.41 & 5,000 & 109 & 39.76 & 4.28 & 0.31 & 13.32 \\
\hline A2-20 & 20 & 1.41 & 2,500 & 53 & 41.06 & 4.77 & 0.27 & 12.95 \\
\hline A $3-20$ & 20 & 1.41 & 1,250 & 25 & 42.46 & 5.22 & 0.27 & 14.49 \\
\hline A $4-20$ & 20 & 1.41 & 625 & 12 & 45.46 & 7.05 & 0.18 & 12.72 \\
\hline
\end{tabular}

Note: ${ }^{\text {a } C r a c k ~ D e n s i t y ~ F a c t o r . ~}$

TABLE 4 Geometry and results from tests with circular specimens in the environmental chamber-fourth series.

\begin{tabular}{|c|c|c|c|c|c|c|c|}
\hline Test & Thickness, cm & Area, $\mathrm{cm}^{2}$ & Number of Cells & $\begin{array}{l}\text { Average Area } \\
\text { of Cells, } \mathrm{cm}^{2}\end{array}$ & $\begin{array}{l}\text { Average Width } \\
\text { of Cracks, mm }\end{array}$ & $\begin{array}{c}\text { Length of Cracks } \\
\text { per Unit Area, } \mathrm{cm}^{-1}\end{array}$ & $C D F^{\mathrm{a}}, \%$ \\
\hline $40-10$ & 10 & 1,257 & 1 & $1,017.86$ & - & - & 19.00 \\
\hline $80-10$ & 10 & 5,027 & 8 & 492.39 & 1.31 & 0.04 & 21.63 \\
\hline 80-10-P & 10 & 5,027 & 10 & 411.45 & 1.12 & 0.06 & 18.15 \\
\hline
\end{tabular}

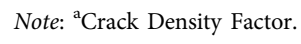

The weight of the specimens was recorded at 30-minute intervals for the first 24 hours and at one-hour intervals for the remaining period until there was no further change in weight. Photographs were taken at the end of each test to be used for image analysis. The initial water contents of the specimens in these series were $30 \pm 0.5 \%$ and $26 \pm 0.5 \%$, respectively.

In Series 3, the specimens were placed over three load cells to record the loss of weight that was due to water evaporation at oneminute intervals. A digital camera was positioned directly above the center of the container to obtain images of the specimen at three-minute intervals, which were to be used for image analysis after the conclusion of the experiments. The experiments were conducted using the same environment-controlled laboratory room as in the previous two series. The initial water content of the specimens was $24 \pm 1 \%$.

A separate objective of the third series was to study scale effects and the use of fracture mechanics principles to model crack formation and propagation in soils. For that, the specimens were monitored carefully to capture the most relevant features such as the onset of the first crack, separation of the soil from the edges of the container, and the points at which the fully cracked and fully dry states were reached. Also, tests were conducted to determine the tensile strength and fracture toughness of the soil. The results proved (Lakshmikantha, Prat, and Ledesma 2012) that cracking in soils does follow fracture mechanics principles and that the size effect follows Bažant's law (Bažant 1984).
In Series 4 , the tests were conducted in the environmental chamber. The imposed environmental conditions $\left(T=35^{\circ} \mathrm{C}\right.$, $R H=40 \%)$ as well as the initial water content $(w \approx 30 \%)$ were the same for all three tests. Recordings of temperature, relative humidity, suction, and weight were continuously made, and images were taken at regular intervals for observation and analysis of the development of the surface crack pattern.

Extensive use is made of image analysis techniques for the evaluation of geometrical parameters, and the results are shown in Tables 1-4. For simplicity, the method developed earlier by the authors (Lakshmikantha, Prat, and Ledesma 2009) was chosen. Characterization of soil properties and features by means of nondestructive methods such as image processing is a growing field (Almhdie et al. 2014; Aydemir, Keskin, and Drees 2004; Liu et al. 2011; Liu et al. 2013; Peng et al. 2006; Shit, Bhunia, and Maiti 2015) not only for geometrical and surface characterization but also for more fundamental soil properties ( $\mathrm{Lu}$ and Kaya 2013). However, the use of more sophisticated image postprocessing was beyond the scope of the work presented in this article.

\section{Results and Discussion}

\section{MORPHOLOGY OF THE CRACK PATTERN}

Fig. 3 shows the effect of thickness on the crack pattern with a rough contact surface between the specimen and the container. 
Fig. 4 shows the final crack pattern of the 8-mm-thick specimens with varying boundary conditions (smooth, rough with circular grooves, and rough with square grid). This figure shows that a smooth contact surface results in smaller width and spacing of the cracks and, therefore, a larger number of cells. There seems to be no noticeable difference between the crack patterns obtained with circular grooves and square grid. Specimens with a smooth bottom soil-container interface develop a perimeter crack as soon

FIG. 5 Average area of cracked cells in circular specimens $(\varnothing 22.5 \mathrm{~cm})$.

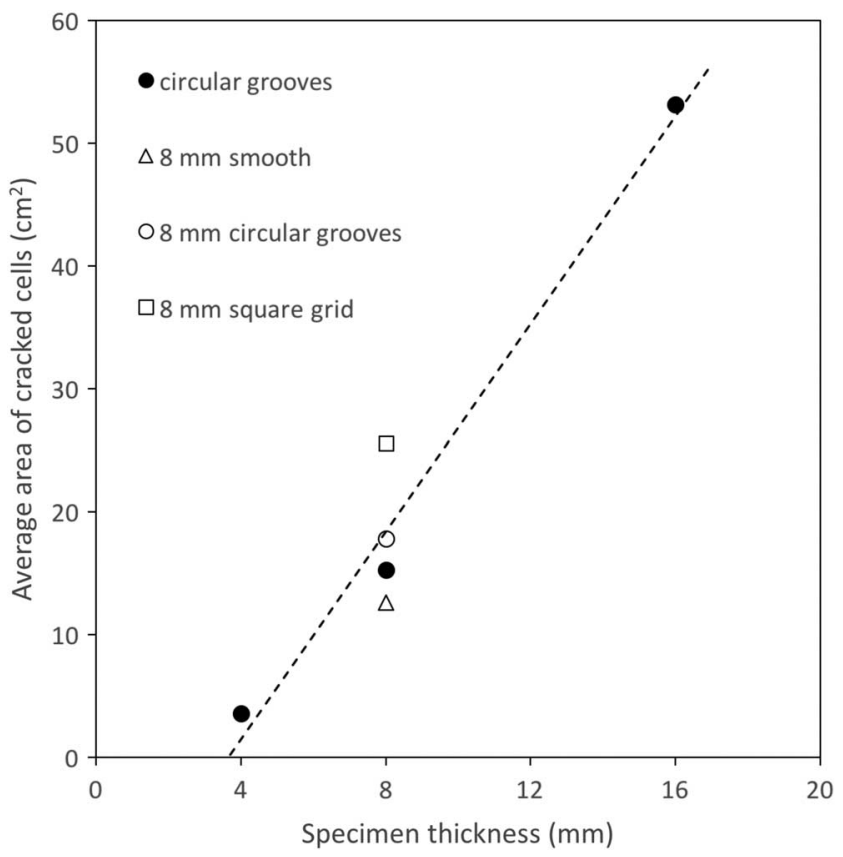

as the consistency becomes solid and horizontal adherence forces start to build at the vertical interface wall between soil and container. After the perimeter crack has formed, secondary cracks begin to appear in the interior of the specimen because of differential drying (Levatti 2015).

As expected from previous research, the spacing and width of the cracks and the area of cells between cracks increase with the thickness of the specimen. Fig. 5 shows the almost-linear relation between the average area of cells and the thickness of the circular specimens.

Fig. 6 shows the crack pattern that developed in the second series of tests. Fig. 6a-e shows the crack patterns in the five specimens of Test \#1 that had approximately the same aspect ratio. Fig. $\mathbf{6 f}$ and $\mathbf{g}$ shows the crack patterns that developed in Tests \#2 and $\# 3$, with aspect ratios of 1 and 2, respectively; all specimens in these tests had a thickness of $10 \mathrm{~mm}$. Fig. $\mathbf{6 h - k}$ shows the crack patterns that developed in Tests \#4 to \#7; all specimens in these tests had thicknesses of $15 \mathrm{~mm}$ and aspect ratios ranging from 1.5 to 4.5. A first look at the crack patterns in Fig. 6 shows a significant difference between the 10-mm-thick (Tests \#1 to \#3) and the 15-mm-thick (Tests \#4 to \#7) specimens: although the specimens in Fig. 6 are not represented to scale, the evidence is that the cells are smaller (and therefore the relative number of cells larger) for specimens with a lower thickness. This was, of course, expected after the results from the preliminary tests with circular specimens.

Closer inspection of these figures shows that specimens with trapezoidal (Test \#1) or rounded (Tests \#4 to \#7) bottom edges become completely separated from the container's walls during the process of drying, thus increasing the effective area where moisture can be lost. However, specimens with perfectly square bottom edges (Tests \#2 and \#3) do not separate, and cracking
FIG. 6

Final crack pattern on rectangular specimens of the second series, Tests 1 to 7 (not to scale): (a)-(e) Test 1, (f) Test 2, (g) Test 3, (h) Test 4, (i) Test 5, (j) Test 6, and (k) Test 7 . (a)

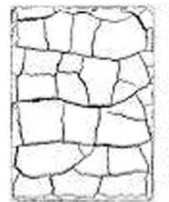

(f)

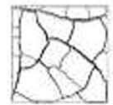

(h) (b)

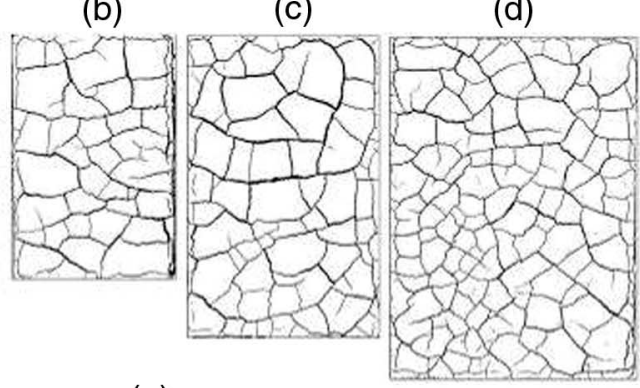

(g)

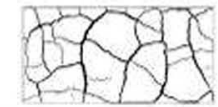

(i)

(j)

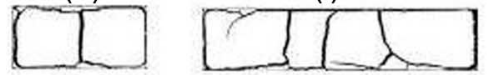

(c)

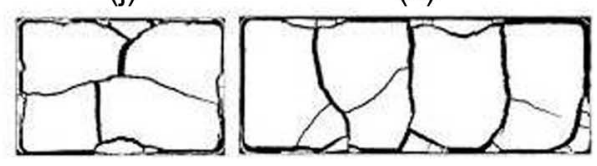

(e)

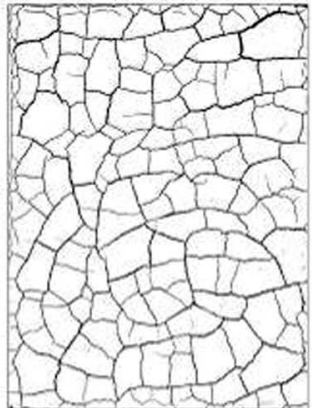

(k) 
occurs in the bulk of the specimen without the formation of a perimeter crack, thereby preventing moisture loss at the sides of the specimen.

The specimens in the third series of tests were constantly monitored with a digital camera. A perimeter crack along the edges developed only in the A4 specimens, regardless of their thickness. The location where the first crack appeared seemed to be random, but it was never in the middle of the specimen: the crack pattern always developed from the edges toward the center. The time at which the first crack appeared varied depending on the size and thickness of the specimen; no clear tendency was observed. However, it was noticeably less for the $10-\mathrm{mm}$ specimens than for the 20-mm specimens. Usually, the cracks propagated in the vertical direction across the specimen's depth. This is probably due to the small thickness of the desiccating specimen, as the thicker specimens tested in the environmental chamber did show inclined cracks and cracks that did not propagate fully across the specimen's depth.

Fig. 7 illustrates the final crack pattern for specimens A0-10 and A0-20, clearly showing that thicker specimens result in wider cracks and larger cells between cracks and, therefore, in less cells. This is also true for the other sizes of specimens (A1 to A4).

Sequential observation of the images recorded during the tests (Fig. 8) reveals that three important mechanisms of cracking, initiation, propagation, and intersecting of cracks happen simultaneously. Another important observation is that cracking occurs sequentially: after primary cracks were first formed, they were followed by secondary, tertiary, and in some cases, quaternary cracks. Fig. 8 illustrates this process, showing images at the appearance of the first crack, several intermediate stages, and the final crack pattern. In the images, the primary cracks can usually be identified because they are wider than other cracks and tend to

FIG. 7 Final crack pattern on rectangular specimens $\mathrm{AO}$ of the third series: (a) 10-mm thick and (b) 20-mm thick (Lakshmikantha 2009).

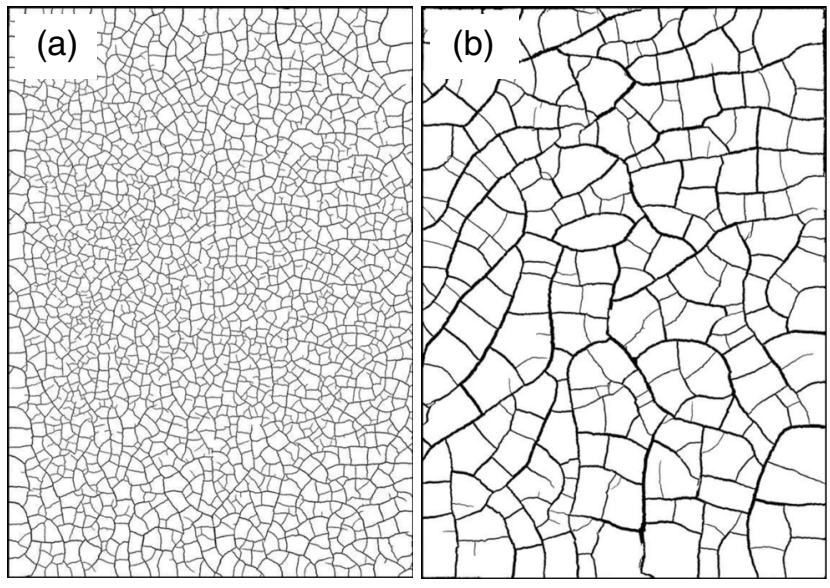

FIG. 8 Evolution of cracking of an A0-20 specimen of the third series: (a) first crack, bottom left; (b)-(e) intermediate stages; and (f) final crack pattern (Lakshmikantha 2009).
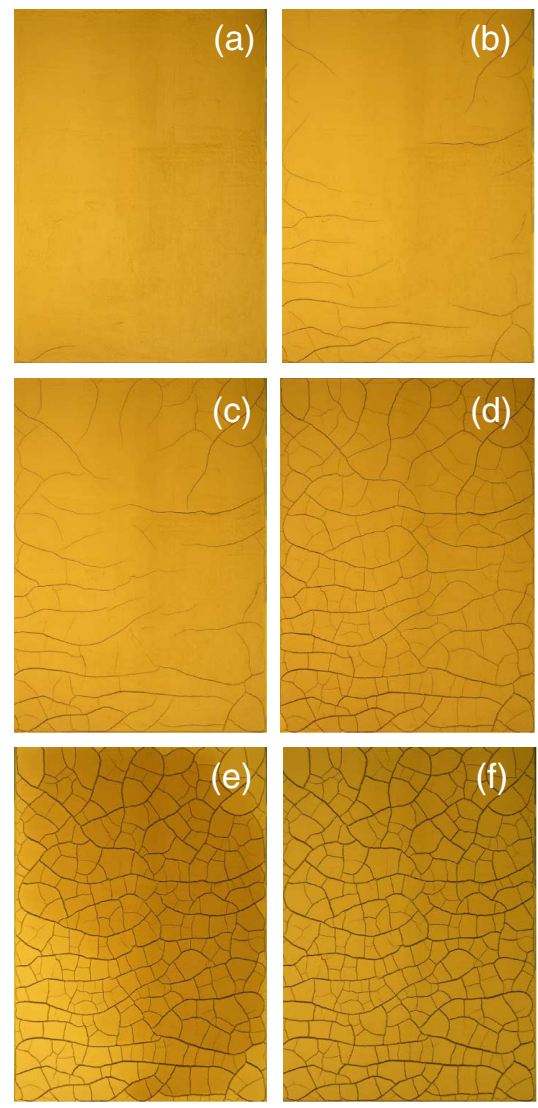

start at the boundaries. This, however, is not trivial and some training is necessary to perform the identification. During the drying process, secondary cracks formed between two primary cracks while the primary cracks were still propagating, the same occurs with tertiary cracks. Some cracks that formed later stopped propagating, leaving a dead-end crack that did not intersect with other cracks. A close observation of the crack patterns in Fig. 7 shows that the majority of cracks that intersect the edges of the container do so at right angles. Additionally, a detailed image analysis of the crack pattern shows that the majority of the cracks intersect other cracks also at right angles (Lakshmikantha, Prat, and Ledesma 2009). This is typical of clays in which cracking is sequential because of tensile failure, leading to orthogonal patterns, while materials in which simultaneous cracking occurs or failure is due to shear result in near hexagonal patterns with intersections at $120^{\circ}$ (Costa, Kodikara, and Shannon 2013; Hartge and Bachmann 2000).

Fig. 9 shows the final patterns obtained from the tests in the environmental chamber (Series 4). The image shows the top (airside) and bottom (container contact) images of each of the three specimens after the test with the location of the sensors. 
FIG. 9

Final crack patterns from tests in the environmental chamber: (a) Test 40-10, top view; (b) Test 40-10, bottom view; (c) Test 80-10, top view; (d) Test 80-10, bottom view (detail A is shown enlarged in Fig. 10): (e) Test 80-10-P, top view; (f) Test 80-10-P, bottom view (cells 1 and 2 are shown enlarged in Fig. 11).
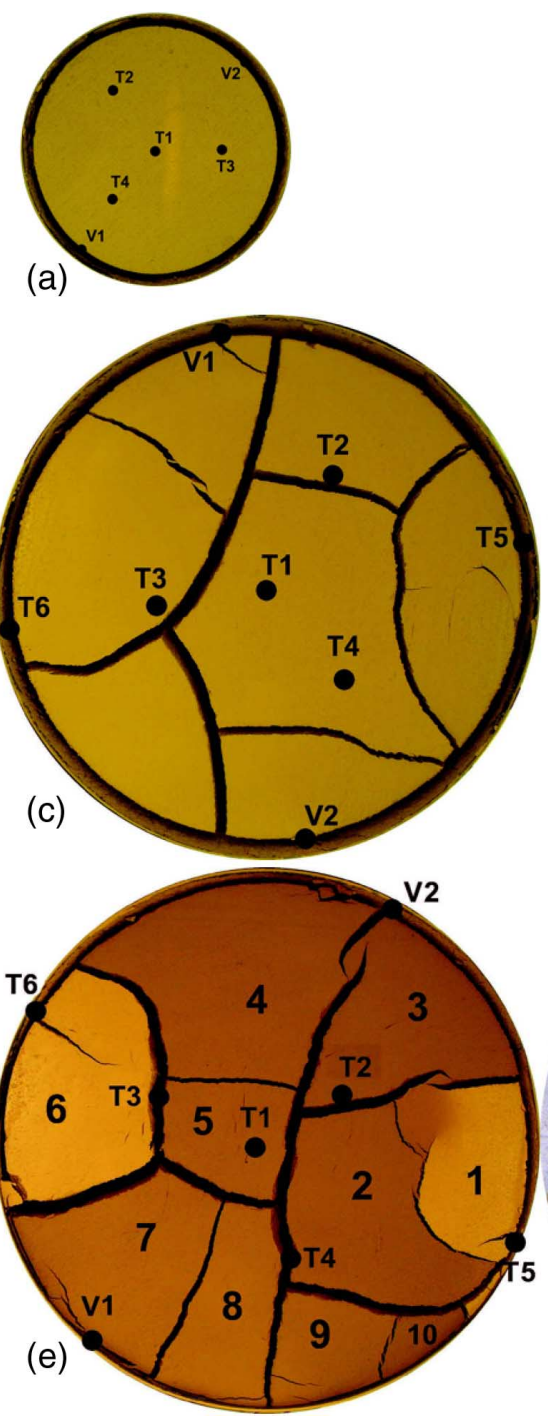

(b)
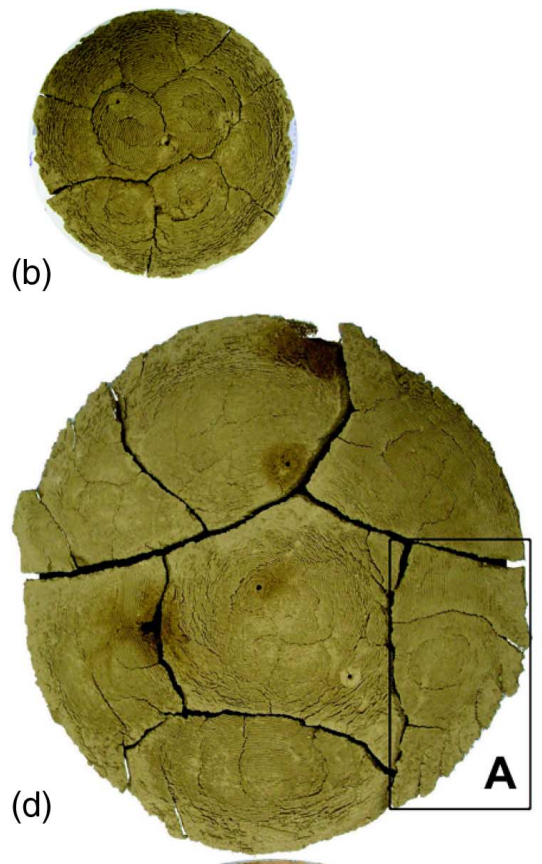

(d)

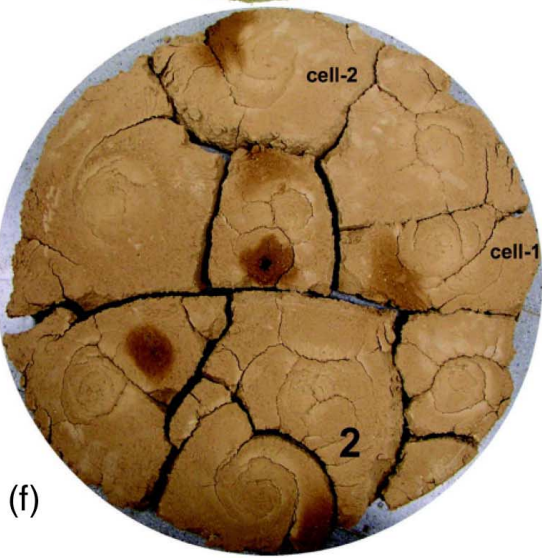

Fig. 9a and $\mathbf{b}$ are from specimen 40-10. The picture shows that no cracks developed on the external surface during the test other than the perimeter crack that started at the upper surface and propagated toward the bottom. At the end of the test the sensors were removed from the specimen and it was turned upside down to observe the conditions at the bottom surface (Fig. 9b). Contrary to the upper surface, the bottom surface shows numerous cracks - the primary cracks having a radial direction, which were perpendicular to the outer perimeter. Some secondary cracks can also be seen on a circular pattern. These curved cracks concentrate in the central part of the specimen, while the radial cracks intersect the curved cracks. The intersections in the crack pattern indicate that the cracks were not formed simultaneously but sequentially. Another morphological feature is that the curved cracks seem to be seamless, while the radial cracks join the curved cracks at right angles, indicating that the radial cracks developed after the curved ones.
The crack formation sequence involving curved and radial cracks has wider implications for the conditions and the mechanism of crack initiation. The radial cracks are likely formed because of a curling phenomenon in which the specimen's bottom surface, in a ring near the outer wall, lifts and becomes in contact, at least partially, with air. Therefore, drying can also occur at the bottom surface. On the other hand, during recovery of the sensors, it was observed that the central portion of the specimen never lost contact with the bottom of the container; thus, curved cracks were also formed without air exposure and under subsurface conditions. This crack formation in subsurface conditions can be attributed to a syneresis process - the contraction of a gel accompanied by the separating out of liquid (Lakshmikantha 2009; Plummer and Gostin 1981; Pratt 1998).

Fig. 9c and d correspond to specimen 80-10 with a rough bottom surface. Fig. $9 c$ shows the upper surface of the specimen at the end of the test. Except for the crack appearing near 
FIG. 10 Detail A of Fig. 9d after dismounting.

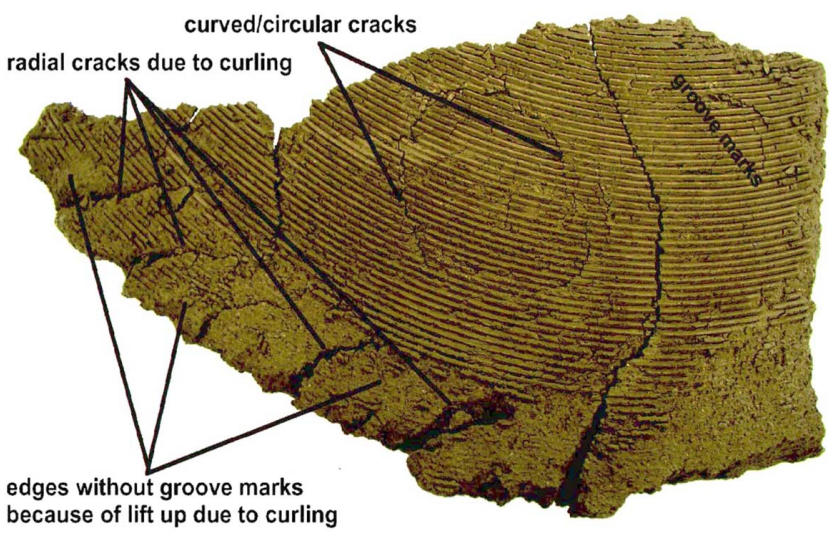

tensiometer $\mathrm{T} 2$, the rest of the cracks intersect the perimeter of the specimen clearly indicating the effect of boundary conditions. Fig. 9d shows the bottom surface of the specimen manually rearranged after removing the sensors. On this surface, several smaller cracks were observed in addition to the main cracks that propagated from the upper surface. Fig. 10 shows a detail of the cell located in the area within the rectangle in Fig. 9d. Groove marks can be seen near the central portion of the cell, but no groove marks appear near the borders because the edges lifted from the bottom surface because of curling. Several cracks start at the edge of the cell and propagate toward the center. However, most of the cracks are likely related to curling and do not reach the center of the cell; instead, they seem to be confined to the lifted area with no groove marks. A well-developed curved crack can be seen at the center of the cell, and a continuous crack traverses the cell starting at the lateral surface of the specimen and propagating toward the center. Because the latter crack is wider, it seems likely that it developed before the curved crack, hence conditioning its further development.

Fig. 9e and f correspond to specimen 80-10-P with a smooth bottom surface. The picture of the upper surface of the specimen at the end of the test (Fig. 9e) shows a crack pattern with ten cells. Only the two cracks forming the edges of cell 1 at the center do not touch the perimeter, indicating the effect of boundary conditions on the crack pattern formation. Fig. 9f shows the bottom surface of the specimen. The details of cells 1 and 2 are shown in Fig. 11 for a better view of the extent to which cracking occurred at the bottom surface. The morphology of the crack pattern is complex, with apparently three mechanisms acting: (1) desiccation from the upper exposed surface; (2) curling that is due to differential shrinkage between the top and bottom of the specimen as a result of desiccation; (3) possibly a syneresis process-sinuous cracks are associated with ripple marks that are common indicators of syneresis processes occurring in either submerged conditions or in substrata and as a response to volume change that is due to shrinkage (Plummer and Gostin 1981). The morphology of
FIG. 11 Detail of cells from Fig. 9f: (a) cell 1 and (b) cell 2.
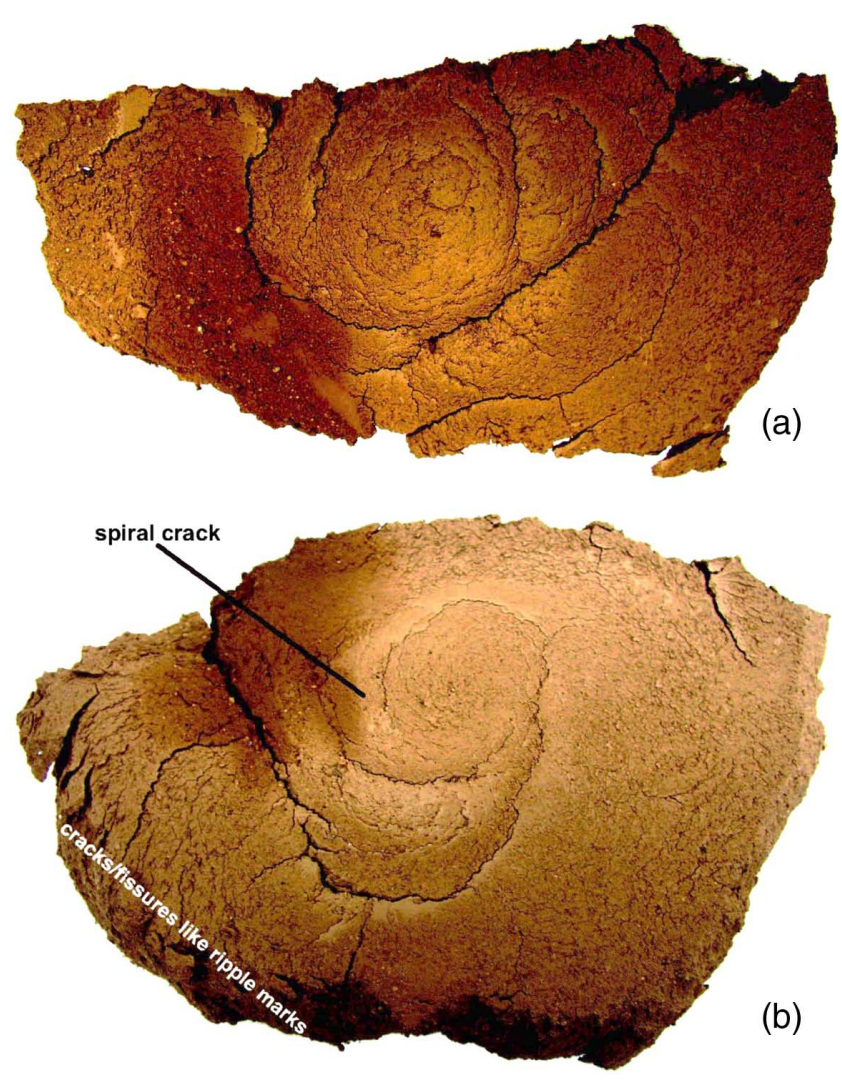

the cracks seen at the cells in Fig. 9f shows spiral cracks and cracks resembling ripple marks, therefore suggesting syneresis (Lakshmikantha 2009).

\section{MOISTURE LOSS AND DESICCATION RATE}

During the tests reported in this article, the change of moisture content was monitored by recording the weight of the specimen at regular intervals. In the first and second series of experiments, the moisture loss was monitored manually, whereas in the third and fourth series, the weight was recorded automatically with three load cells connected to a data acquisition system. The desiccation rate and desiccation coefficient were calculated using the modified definition of Nahlawi and Kodikara (2006) that extends the original definition of Corte and Higashi (1960) by considering the residual moisture content at the final stage, $w_{r}$, so that the soil's moisture content never reaches a zero value:

$$
\left(w-w_{r}\right)=\left(w_{0}-w_{r}\right) e^{-k t}
$$

where $w_{0}$ is the initial moisture content of the soil, $w$ is the moisture content of the soil at time $t$, and $k$ is the desiccation rate coefficient with dimensions $[k]=T^{-1}$.

The desiccation rate is defined as the absolute value of the slope of the moisture content versus time relationship, 
FIG. 12

(a) Moisture loss with time for circular specimens 4-, 8-, and 16-mm thick; (b) desiccation rate coefficient for circular specimens of the same drying surface area with different thicknesses.

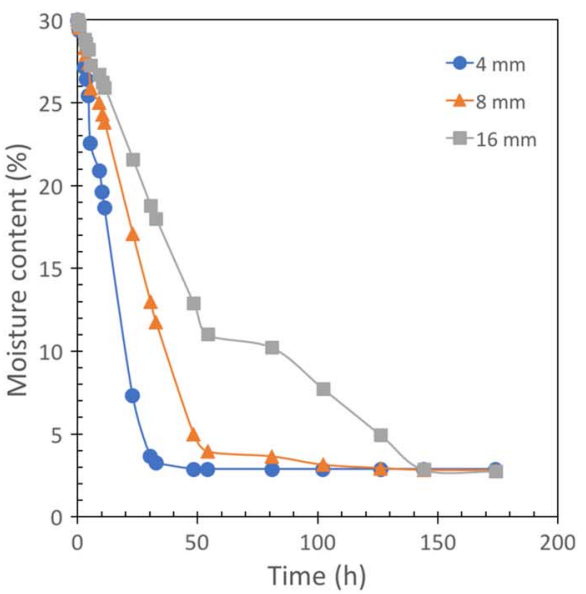

(a)

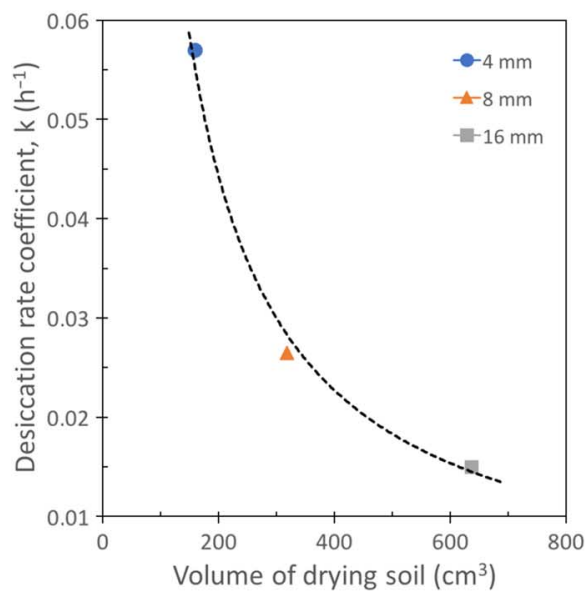

(b) $|d w / d t|$, so that the initial value is $-k\left(w_{0}-w_{r}\right)$, from which it is apparent that the desiccation rate is proportional to the desiccation coefficient.

The moisture changes in the first series with circular specimens are shown in Fig. 12a. The desiccation rate coefficient was larger for thinner specimens, clearly showing the effect of thickness (Fig. 12b); this is a fact that is extensively reported in the literature (Corte and Higashi 1960; Nahlawi and Kodikara 2006): if the thickness increases while keeping the drying surface area constant, it follows that the rate of moisture loss should decrease because water has to travel longer distances to evaporate (Nahlawi and Kodikara 2006). In these tests, doubling the thickness resulted in a desiccation rate of about one-half. As expected, the three specimens reached the same final moisture content but, depending on the thickness each specimen, reached this final stage at different times, with the thinner specimen being the first.

Fig. 13 shows the moisture changes in the second series with rectangular specimens of different geometries. For Tests \#2-7, the results are the average of the three specimens used in each test. The time taken to reach the residual moisture content ranges from about 75 hours to about 150 hours, depending on the specimen geometry. The rate of moisture loss ranges from 0.181 (Test \#4) to 0.413 (Test \#1d). In general, this rate tends to decrease with an increasing aspect ratio of the specimen and tends to increase with the surface area of the specimen. Thickness also affects the rate of moisture loss, with smaller values for thicker specimens.

Fig. 14 represents the changes in the moisture content in the third series, showing two groups of tests having different rates of moisture loss, with the $10-\mathrm{mm}$ specimens reaching equilibrium in about half the time of that of the 20 -mm specimens. Equilibrium is reached with about $2 \%$ of residual water content. The results of this third series showed also that the rate of moisture loss increases with the surface area of the specimen. This is more
FIG. 13 Moisture loss with time of rectangular specimens of different geometries and thicknesses: $10 \mathrm{~mm}$ (Tests 1-3) and $15 \mathrm{~mm}$ (Tests 4-7).

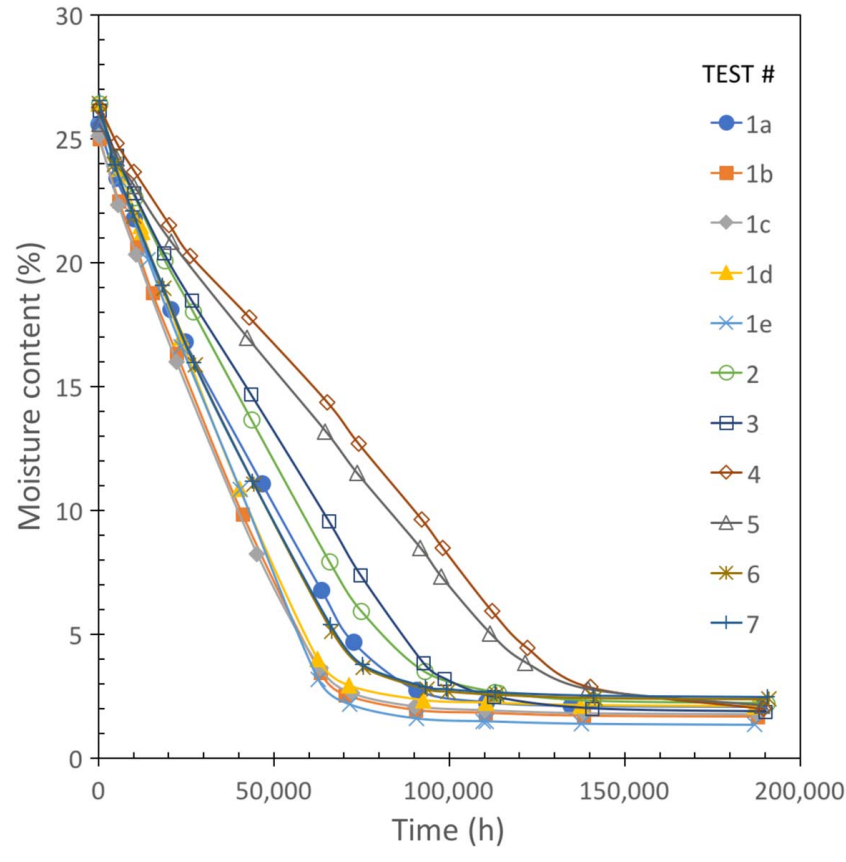

noticeable in the 10 -mm-thick specimens. The time required to reach the same state of desiccation for identical specimens in different environments is different, and this time is different as well for specimens of different thicknesses dried in the same environment. Therefore, desiccation rate, thickness, and environment are interdependent.

Moisture loss from the drying soil surface is by evaporation, which involves a state change of the water from liquid to vapor. For the process of evaporation to take place on a surface, there 
FIG. 14 Moisture loss with time of rectangular specimens of a similar geometry.

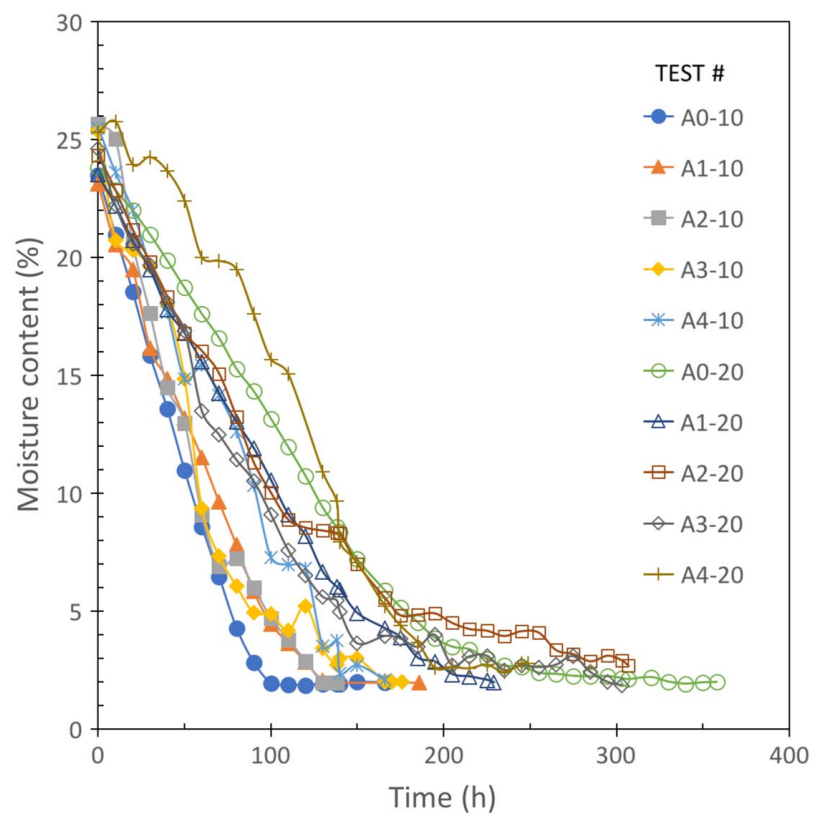

must be an input of energy to bring about this change of state. This energy may come from different sources, with heat being a major energy supplier to trigger the water's state change, although other sources, such as variations in vapor concentration, may also trigger water evaporation from the soil. In nature, solar radiation is the main source of this thermal energy. For evaporation, latent heat and sensible heat are important sources to be considered, both depending on surface area. And in the case of soils, the bulk of thermal energy exchange takes place by conduction, the transfer of heat energy by intermolecular contact, which depends also on the drying surface area.

The main variables of the desiccation process are as follows: the surface evaporation area $(A)$; the thickness $(d)$; the temperature $(T)$; the relative humidity $(R H)$; the suction $(s)$ and the desiccation rate coefficient $(k)$. Temperature, relative humidity, and suction are further related through the psychrometric law:

$$
R H=100 \exp \left(\frac{-s \cdot M_{w}}{R \cdot T \cdot \rho_{l}}\right)
$$

where $M_{w}=0.018 \mathrm{~kg} / \mathrm{mol}$ is the molecular mass of water, $R=8.314 \mathrm{JK}^{-1} \mathrm{~mol}^{-1}$ is the gas constant, and $\rho_{l}=1,000 \mathrm{~kg} / \mathrm{m}^{3}$ is the water density.

The rate of desiccation depends essentially on the thickness of the specimen and on its contact surface with the atmosphere. Thicker specimens present smaller rates of desiccation because water has to travel a longer distance to evaporate, while specimens with larger surface areas present larger rates because there is more contact area between soil and air, which increases evaporation.
The initial moisture content also plays a role: in equal conditions, if the moisture content is larger, there is more water available in a relatively free state for evaporation; therefore, the water can escape faster with the same available heat energy, resulting in a higher rate of desiccation.

The results of the tests conducted in the environmental chamber (Series 4) are reproduced in Fig. 15 (specimen 40-10), Fig. 16 (specimen 80-10), and Fig. 17 (specimen 80-10-P). Figs. 15a, 16a, and 17a all show the time evolution of air and soil temperature and relative humidity as well as the moisture loss or desiccation curve. Figs. 15b, 16b, and 17b show the variation of suction during the early stages of the tests (first 10 to 14 days, depending on the specimen) taken directly from the tensiometers before they reached cavitation and after the soil around them became unsaturated. Figs. 15c, 16c, and 17c show the evolution of suction after the soil became unsaturated and is calculated using the psychrometric law, Eq 2, from the relative humidity and temperature of the soil recorded by the Vaisala sensors V1 and V2 (see Fig. 9). The gaps, discontinuities, and other apparent inconsistencies that appear in the three figures are due to incidents during the tests, such as power failures or the opening of the environmental chamber for minor maintenance. After the incidents, the readings recovered the original trend after a short stabilization period.

In the smaller specimen (40-10, Fig. 15), the moisture content reached equilibrium approximately 33 days after the start of the test. The relative air humidity in the environmental chamber was maintained at $40 \%$ with little variations, and the air temperature was maintained at $35 \pm 0.2^{\circ} \mathrm{C}$. The soil temperature quickly rose to a value slightly less than the imposed chamber temperature and remained that way until around day 30 , where both temperatures became equalized until the end of the test. The suction measured by tensiometers T1-T4 reached the maximum value at approximately ten days after the beginning of the test. The initially low readings from the central tensiometer $\mathrm{T} 1$ can be attributed to the fact that the specimen dries from the periphery to the center. Because of the specimen's small size, tensiometers T5 and T6 at the soil-container interface were not used in this test. The suction values calculated from both sensors (V1 and V2) using the psychrometric law appear to be similar because of the absence of cracks on the upper surface.

In the larger specimen with a rough bottom soil-container interface (80-10, Fig. 16), the air temperature shows slight variations of $\pm 0.2^{\circ} \mathrm{C}$ from the imposed $35^{\circ} \mathrm{C}$. The relative humidity was kept between $0.2 \%-4 \%$ of the imposed $40 \%$, and the soil moisture reached equilibrium after 35 days of drying. The soil temperature in this case quickly rose to a value near $30^{\circ} \mathrm{C}$ and remained stable at that temperature until the large increase in the relative humidity rate on day 23 ; after that, the soil temperature slowly increased toward a value similar to the air temperature at the end of the test. The evolution of the various parameters is explained by choosing six transition points 
FIG. 15 Time evolution of different parameters for specimen 40-10 during testing in the environmental chamber: (a) air and soil temperature and relative humidity, soil moisture loss; (b) suction recorded from tensiometers T1-T4 during the initial stages of the test; (c) suction calculated from relative humidity and temperature data using the psychrometric law (2). For location of sensors, see Fig. 9a.

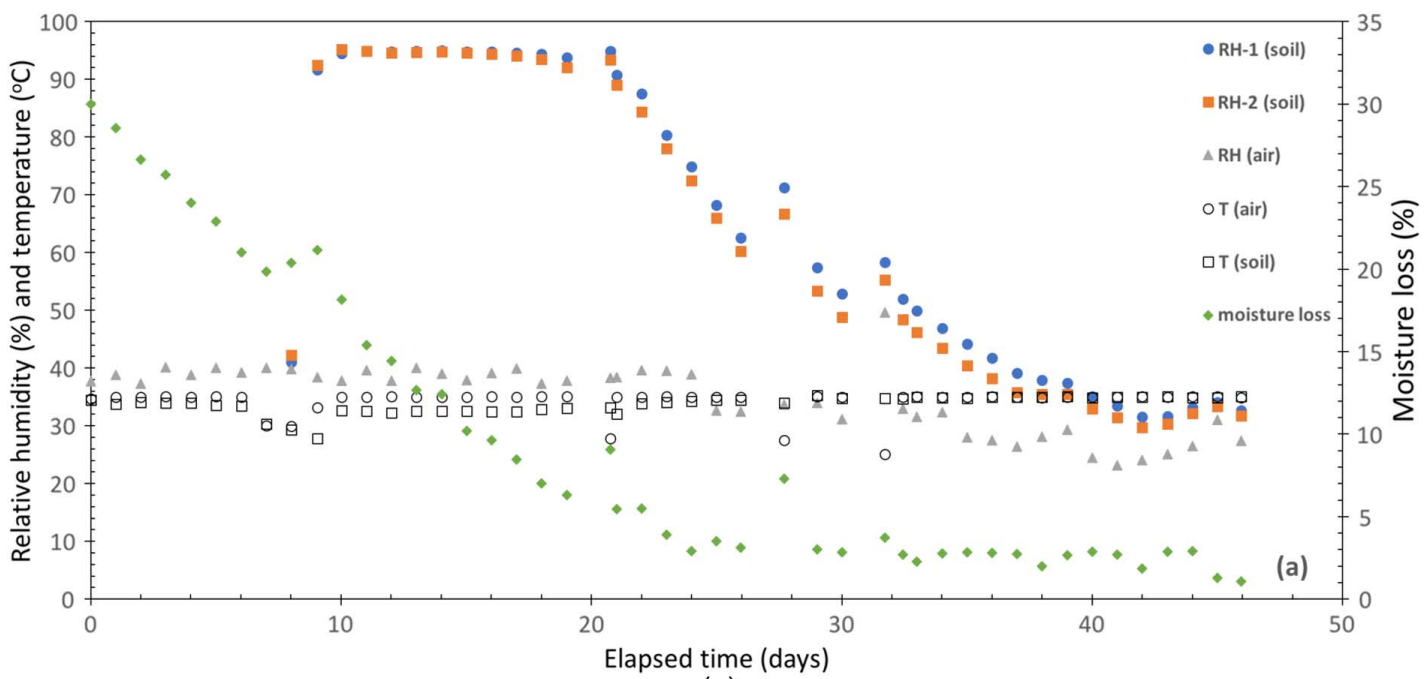

(a)

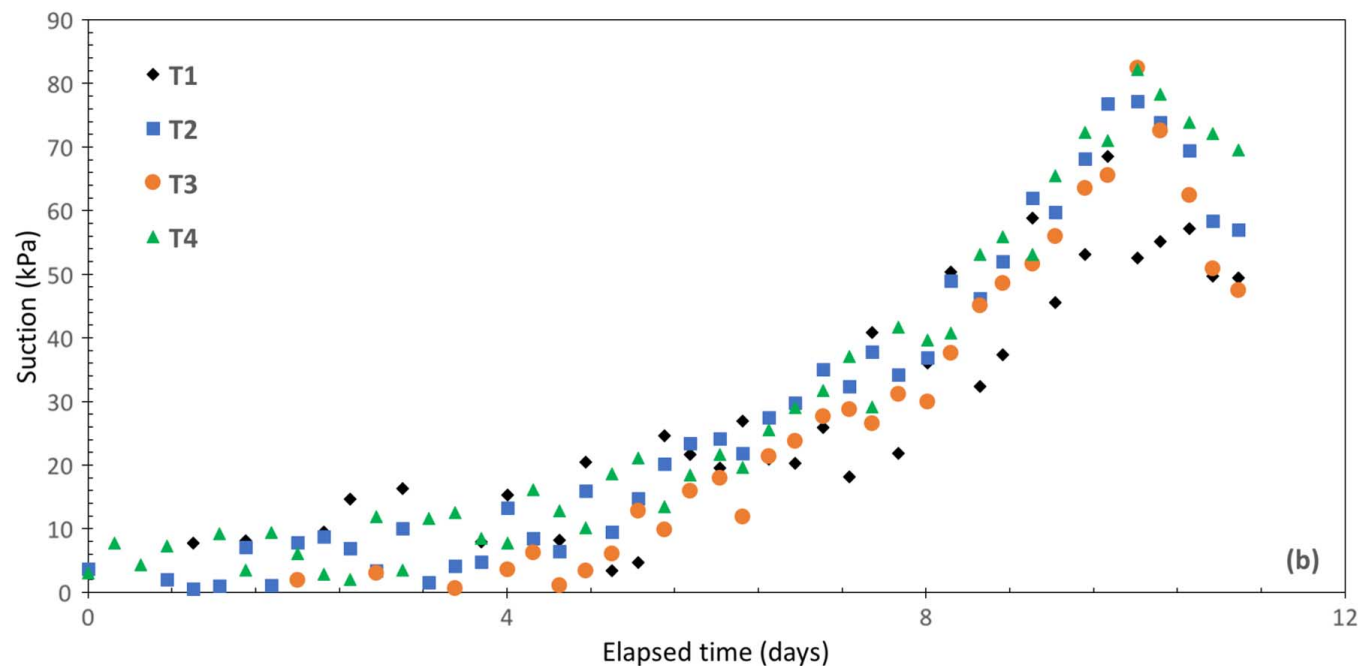

(b)

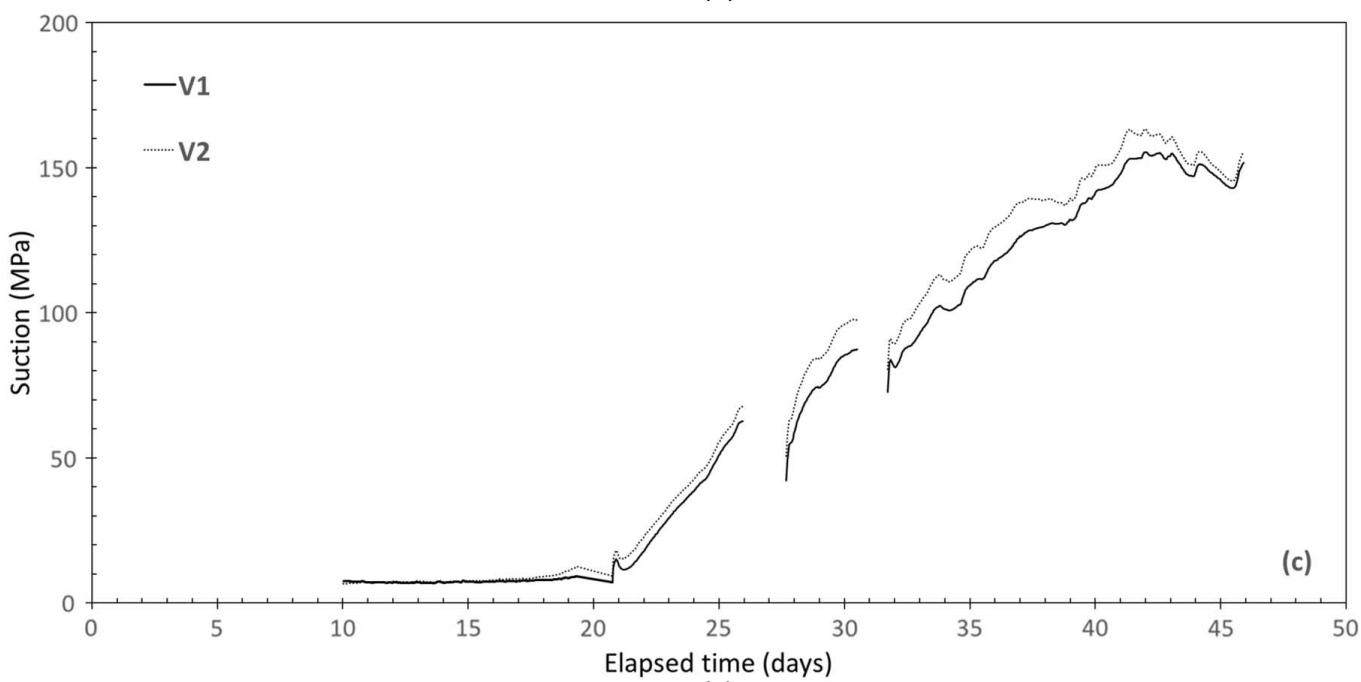

(c) 
FIG. 16 Time evolution of different parameters for specimen 80-10 during testing in the environmental chamber: (a) air and soil temperature and relative humidity, soil moisture loss; (b) suction recorded from tensiometers T1-T6 during the initial stages of the test; (c) suction calculated from relative humidity and temperature data using the psychrometric law (2). For location of sensors, see Fig. 9c.
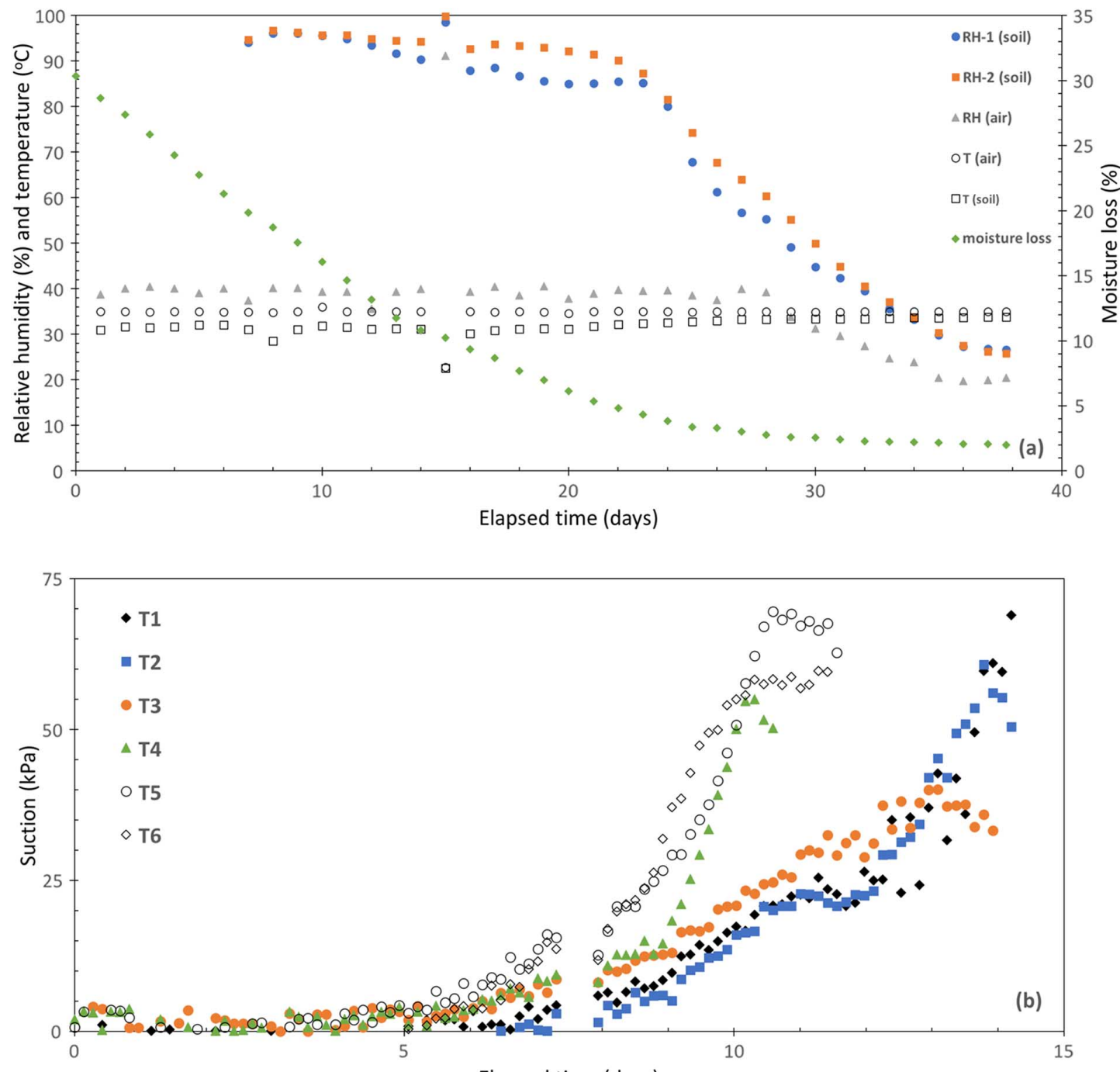

Elapsed time (days)

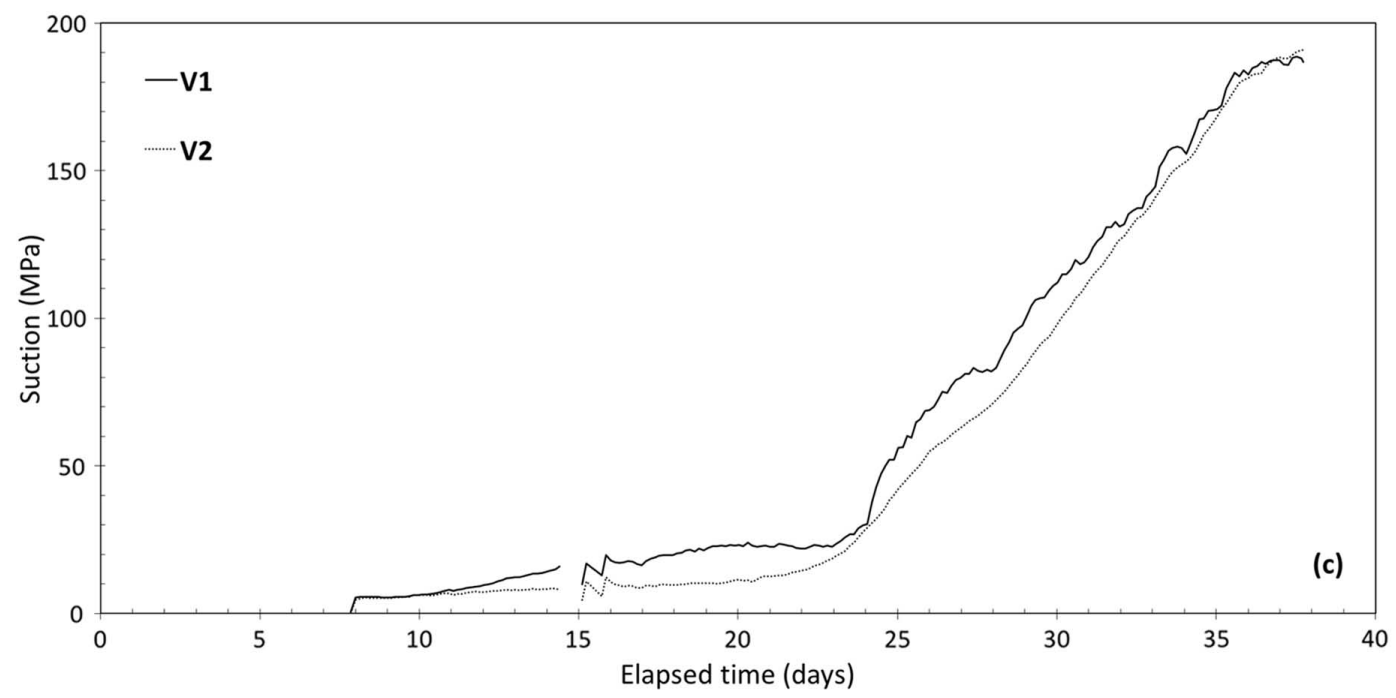


(see Fig. 9c): (1) the first fully formed crack was observed on day 8 , near tensiometer T5, but it did not propagate; (2) a small crack was observed on day 11 above sensor V1, which resulted in a slightly smaller rate of relative humidity loss recorded by sensor V1 than by sensor V2, indicating the effect of crack formation on the surrounding moisture conditions; (3) on day 20, more than $80 \%$ of moisture loss had taken place and the soil temperature started to increase slightly faster; (4) on day 23, the large moisture loss resulted in a large change of the slope of the soil relative humidity curve; (5) from day 27 onward, the moisture loss curve was practically flat; (6) on day 37, equilibrium between the air and soil temperatures and relative humidity was reached and, as a result, the moisture content of the soil stabilized with no further losses.

Fig. 16b shows the evolution of suction during the initial stage of the experiment (first 15 days) measured by the tensiometers. The maximum suction recorded by the tensiometers was in the $60-70 \mathrm{kpa}$ range, except for tensiometer $\mathrm{T} 3$, which reached a suction of only $40 \mathrm{kPa}$ before cavitation. The time taken to reach this maximum value of suction was smaller for the tensiometers located on the periphery (T5, T6) than for the one at the center (T1), showing the progression of the drying front. Although readings from tensiometer $\mathrm{T} 4$ could be expected to be comparable to tensiometers $\mathrm{T} 2$ and $\mathrm{T} 3$, the results show that $\mathrm{T} 4$ reaches the maximum value about four days earlier than $\mathrm{T} 2$ and T3. This can be explained by the position of the tensiometers with respect to the heating lamps, T4 being closer than T2 and T3, therefore making the specimen dry sooner around the T4 location.

The suction after day 10 calculated from the relative humidity and temperature using the psychrometric law shows slightly different values from sensors V1 and V2; this can be explained by the presence of a crack above sensor V1, illustrating the effect of cracking on the rate of desiccation. From day 25, the rate of suction increase in the two sensors is about the same because the crack near sensor V1 could not develop further and the soil moisture remained the same throughout the specimen.

In the test with the larger specimen with a smooth bottom soil-container interface (80-10-P, Fig. 17), the chamber air temperature and relative humidity show similar trends to the test with a smooth soil-container interface: the air temperature remains within $\pm 0.2^{\circ} \mathrm{C}$ of the imposed $35^{\circ} \mathrm{C}$, and the relative humidity remains within $0.2 \%-4 \%$ of the imposed $40 \%$. In this case, the soil moisture reaches equilibrium after 25 days of drying. As in the previous test, the soil temperature quickly rose to a value near $30^{\circ} \mathrm{C}$ and remained stable at that temperature until the large increase in the relative humidity rate recorded by sensor V2 on day 10. From that day, the soil temperature slowly increased toward a value similar to the air temperature at the end of the test. In this case, the difference of the recordings between sensors V1 and V2 is due to the large radial crack, in addition to the perimeter crack, that developed at the location of sensor V2, whereas there are no radial cracks at the location of sensor V1 and the perimeter cracks there are thinner.

The evolution of the parameters depicted in Fig. 17 is explained by choosing six transition points (see Fig. 9e): (1) a first crack started one day after initiation of the test, propagating from the outer perimeter of cell number 6 above tensiometer T1; until day 3, no significant development of the crack was observed and it was not until day 6 that a fully developed crack could be seen; (2) around day 10, a fully developed crack was observed above sensor V2, which resulted in a much faster rate of decrease on the relative humidity compared to sensor V1, indicating the effect of crack formation on moisture conditions; (3) on day 20, around $80 \%$ of moisture loss had taken place and the rate of decrease of relative humidity in sensor V2 (measuring around $60 \%$ ) was reduced; at the same time the relative humidity around sensor V1 was still greater than $90 \%$; (4) on day 22 , the relative humidity rate recorded by sensor $\mathrm{V} 1$ shows a considerable increment linked to the formation of some small cracks located near the sensor; at the same time, the relative humidity around sensor V2, which has a crack above it, shows a rate decrease; (5) from day 26 onward, there was no further increment in soil temperature, remaining almost equal to the imposed air temperature; the moisture loss curve was practically flat, and the humidity control device was not triggered anymore because the quantity of evaporating water could not increase the humidity of the volume of air inside the environmental chamber; (6) around day 34 , an equilibrium between the air and soil temperature and relative humidity was reached and, as a result, the moisture content of the soil stabilized with no further losses.

Fig. 17b shows the evolution of suction during the initial stage of the experiment (first 14 days) measured by the tensiometers. During the first four days, the measured suction did not vary significantly, indicating that the soil specimen was fully saturated. After that time, the rate of suction change in tensiometer T5 was larger than in the rest. The rate of suction change in tensiometers T6 and T4 started to increase after six days. Suction values before day 8 were lower than $10 \pm 3 \mathrm{kPa}$ in tensiometers T1-T3 and started to increase thereafter. The maximum suction recorded by the tensiometers was in the $60-100 \mathrm{kpa}$ range, except for tensiometer T2, which did not show any change of suction because of a malfunction and is not represented in the figure. The time taken to reach the maximum suction recorded by the tensiometers increased from the ones at the periphery toward the one in the center. Tensiometer $\mathrm{T} 5$ was the first to reach the maximum at about 5.6 days, followed by T6 at about 7.2 days, T4 at about 7.6 days, and $\mathrm{T} 3$ at about 10 days (the difference between sensors T3 and T4 is explained by the fact that the cracks at their locations formed at different times, therefore drying at sensor T4 occurring earlier than that at sensor T3). Tensiometer T1 was the last to reach its peak at about 13.6 days. The evolution of suction shows a similar behavior in comparison to Test 80-10 with a rough bottom surface. 
FIG. 17 Time evolution of different parameters for specimen 80-10-P during testing in the environmental chamber: (a) air and soil temperature and relative humidity, soil moisture loss; (b) suction recorded from tensiometers T1 and T3-T6 during the initial stages of the test; (c) suction calculated from relative humidity and temperature data using the psychrometric law (2). For location of sensors, see Fig. 9e.

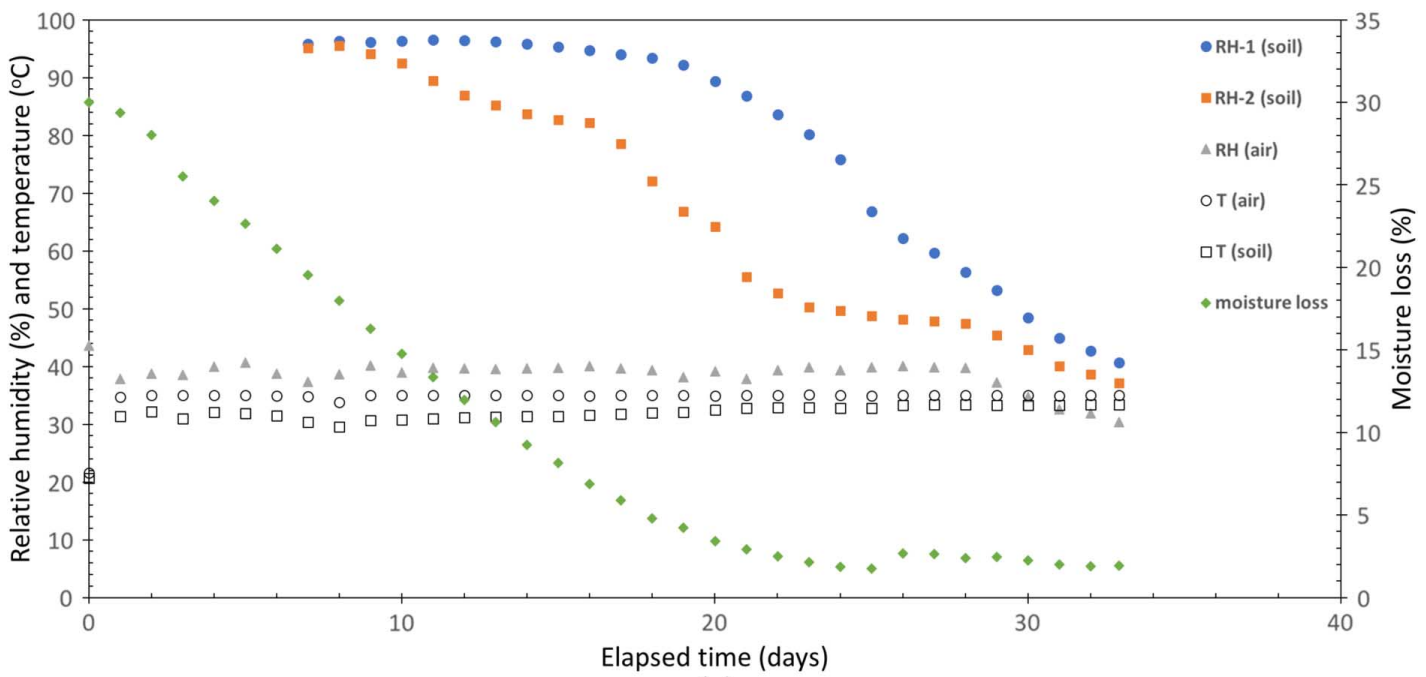

(a)

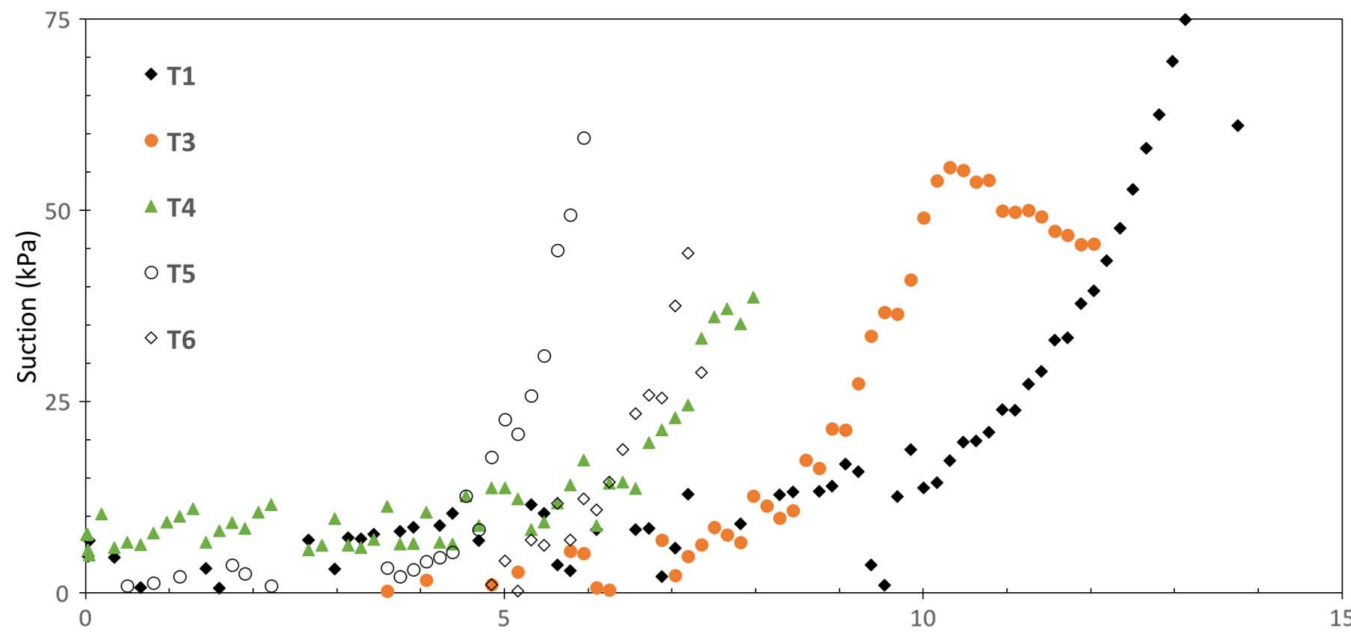

Elapsed time (days)

(b)

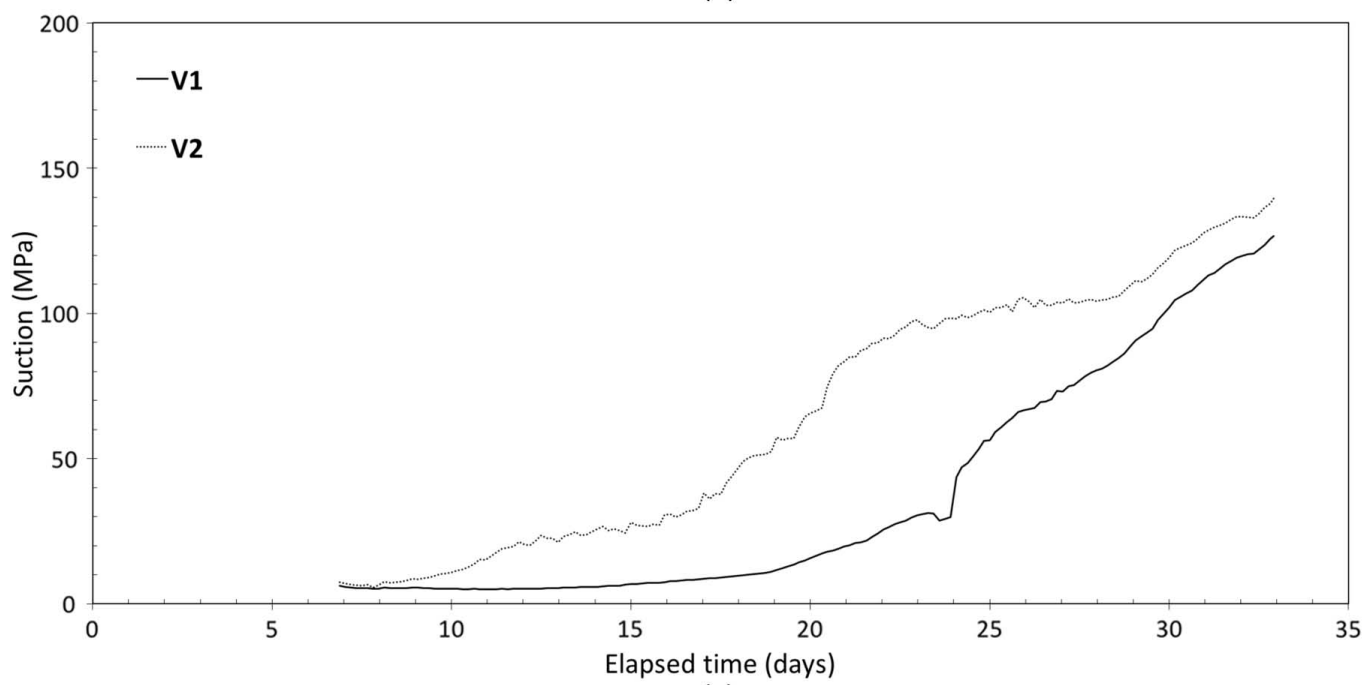

(c) 
The suction after day 6 calculated from the relative humidity and temperature using the psychrometric law shows significantly different values from sensors V1 and V2. At least at the points where the sensors were located, the specimen remained almost saturated until day 6. From there onward, the suction increased only in sensor V2, while sensor V1 desaturated at a lower rate. This difference in behavior is due to the presence of the crack above sensor V2. At around day 34, the rate of suction increase in the two sensors was about the same.

\section{CRACKING WATER CONTENT}

There is no consensus on what the conditions are for crack initiation. Shin and Santamarina (2011) suggest that defects on the soil surface constitute the points where cracks initiate-typically when suction reaches the air-entry value of the soil. On the contrary, Ávila, Ledesma, and Lloret (2013) indicate that the stress field dominates the crack initiation. It seems that both conditions apply in practice. A simple approach is based on the comparison of the tensile stress with the tensile strength of the soil. The stress field depends on boundary conditions and the shrinkage deformation imposed, whereas the tensile strength depends on the water content or suction. In Lakshmikantha, Prat, and Ledesma (2012), the water retention curves and tensile strength curves for this soil at different densities were published. The correct interpretation of the experiments requires a consideration of the thermo-hydro-mechanical equations involved, including the appropriate initial and boundary conditions. This is actually an ongoing research task, and it is outside the scope of this article. The procedure follows partly the basic approach from Rodríguez et al. (2007) that involves at least a hydro-mechanical coupled analysis considering the following aspects: the equilibrium equation for the solid, the water mass balance equation including Darcy's law for the liquid under unsaturated conditions, a constitutive law predicting volumetric strains from total stresses and suction, and, finally, a strength criterion (i.e., soil fails when tensile stress reaches tensile strength). There is, however, some evidence that shear stresses may be significant in this context because angles between cracks are different than $90^{\circ}$ (see previous figures showing crack patterns). That could be related to the fact that suction confines soil in all directions and, therefore, mode-I fracture may not prevail as shear stresses develop (Ávila, Ledesma, and Lloret 2013). It is expected that numerical calculations will help in interpreting these aspects of the experiments. However, a qualitative analysis is always useful for obtaining a first insight into the mechanics of the initiation and propagation of the cracks.

The cracking water content is the water content at the time of appearance of the first crack. Evaluation of this value requires knowledge of the time at which the first crack appears, as well as of the water content at that time. For the present tests, the time was determined from the image analysis of the sequence of pictures taken during the tests, which allows for the visualization of when the first crack appears. Once the time of the first crack is
FIG. 18 Relation of cracking moisture content and desiccation rate coefficient for rectangular specimens of the third series.

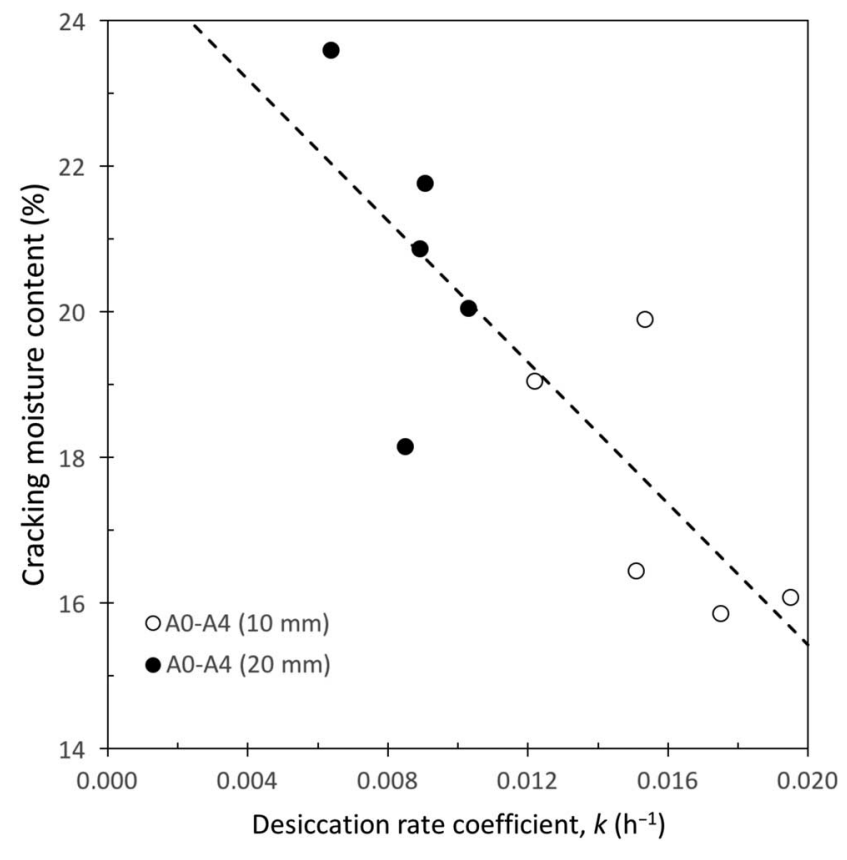

determined, the water content at the same time is obtained from the moisture loss versus time curves already known. Fig. 18 shows the relation between the cracking water content and the desiccation rate coefficient for the third series of experiments. This figure illustrates that the cracking water content increases with the thickness of the specimen, and that it decreases as the desiccation rate coefficient increases, as previously reported in the literature (Corte and Higashi 1960; Nahlawi and Kodikara 2006; Rodríguez et al. 2007).

Fig. 18 also indicates that the water content at crack initiation is slightly different for several similar tests. Indeed, for experiments of the third series and with a $20-\mathrm{mm}$ thickness, the water content ranges from $18 \%$ to almost $24 \%$, whereas for 10 -mm-thick specimens, the range is $16 \%$ to $20 \%$. Each range in water content at crack initiation may be due to heterogeneities of the soil or to an odd suction-saturation distribution within the soil mass (average water content measured values are different from local values). These values do not confirm that the air-entry value is the suction at which crack initiates. Clearly the stress field plays a role because, depending on the thickness, water content at crack initiation is different.

From the image analysis carried out on the specimens during the experiments (Lakshmikantha, Prat, and Ledesma 2009, 2012), it was observed that after reaching a certain stage during the drying process no major cracks initiated or propagated that resulted in a new crack surface, marking the end of severe cracking. This stage is reached when a further increase of the tensile stress does not result in the nucleation of new cracks. Fig. 19 shows the 
FIG. 19 Relation of moisture content and desiccation rate coefficient at the end of severe cracking for rectangular specimens of the third series.

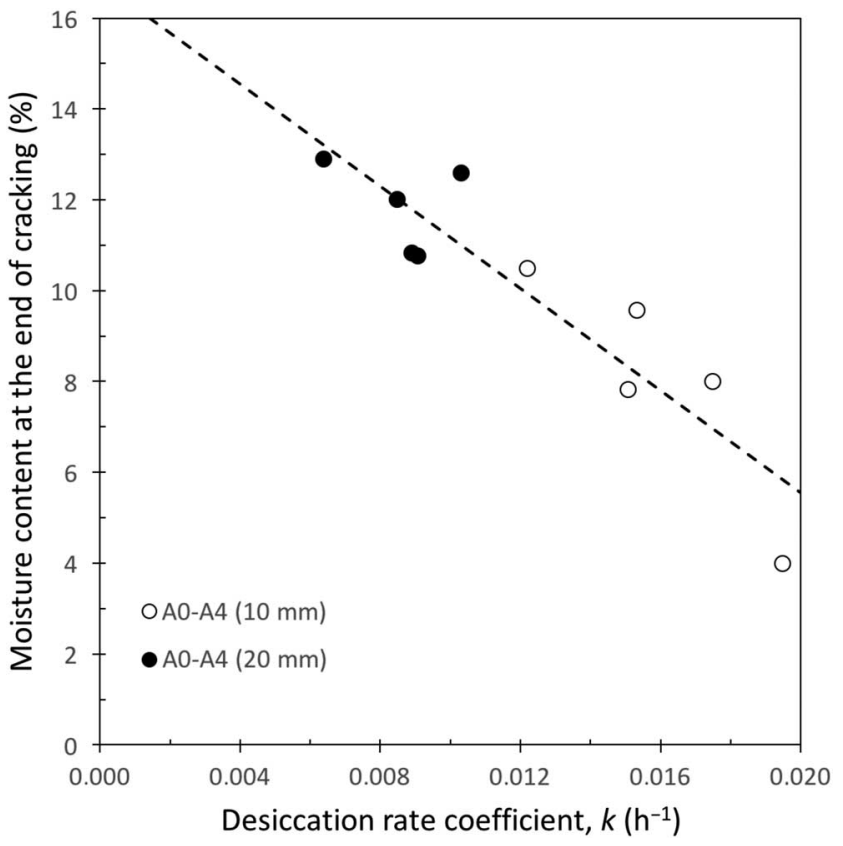

relationship between the desiccation rate coefficient and the moisture content at the end of the severe cracking stage corresponding to the third series of tests. This moisture content at the end of the severe cracking stage follows similar trends as the cracking moisture content.

\section{CRACK PATTERN CHARACTERISTICS}

The investigation into the pattern structure of the crack network as it evolves during drying was performed using a method previously developed by Lakshmikantha, Prat, and Ledesma (2009). The method yields several parameters that can be used to characterize the crack network: the number of cells into which the specimen is divided, the average area of those cells, their aspect ratios, the average crack width, the crack density factor or $C D F$ (Miller, Mi, and Yesiller 1998), etc. The summary of the results of the image analysis is given in Tables 1-4 for the four series, respectively.

The crack density factor is used to characterize the extent of surface cracking. It is defined as the ratio of total crack area to the total virgin surface area of the drying specimen. The results shown in Table 2 indicate that for the second series of tests, the single factor influencing the crack density factor is the specimen's thickness (average values are $C D F_{10}^{(2)}=8.63 \%$ and $C D F_{15}^{(2)}=13.50 \%$ ). Similar conclusion can be made from the third series of tests shown in Table 3 (average values are $C D F_{10}^{(3)}=10.2 \%$ and $C D F_{20}^{(3)}=$ $13 \%)$. The difference between the $C D F$ values of the $10-\mathrm{mm}$-thick specimens of the second and third series of experiments can be attributed to the different initial moisture contents and desiccation rates.

Some selected images of the specimens corresponding to the third series were analyzed to obtain an overall picture of the crack evolution and of the main stages of crack formation such as crack initiation, severe cracking period, rate of crack growth, and end of cracking. These can be evaluated from the moisture content loss and crack density factor versus time curves depicted in Fig. 20.

Regarding friction at the specimen-container interface, Corte and Higashi (1960) concluded from their tests that less friction results in smaller areas of the cracked cells. Similarly, Groisman and Kaplan (1994) concluded that crack formation was reduced with less friction. The effect of friction was investigated in the present work only with circular specimens; the conclusion was that friction did not affect the CDF of the final crack pattern $(20.58,19.92$, and $20.21 \%$ for smooth, circular grooves, and square grid, respectively). However, it did have an effect on the number of cells $(25,19$, and 12 , respectively) and on the average area of the cells $\left(12.64,17.82\right.$, and $25.62 \mathrm{~cm}^{2}$, respectively). The smooth surface offered the least friction, whereas the square grids offered the greatest.

The average area of the cells can serve as a substitute for the crack spacing measurement and has been adopted as the characteristic measure instead of the commonly used crack spacing, which is perhaps an easier variable to measure in strip-like specimens. However, for large circular and rectangular specimens with nominal surfaces as large as $1 \mathrm{~m}^{2}$ and with thousands of cracks, the average area of the cells represents a qualitatively better crack pattern, whereas the spacing between cracks becomes difficult to determine because cracks are seldom parallel.

The average crack width is also affected by the thickness. Table 2 shows that in Series 2 the average crack widths are $w_{10}^{(2)}=$ $1.10 \mathrm{~mm}$ and $w_{15}^{(2)}=2.92 \mathrm{~mm}$ for the 10 - and 15-mm-thick specimens, respectively; for the third series (Table 3), $w_{10}^{(3)}=1.90 \mathrm{~mm}$ and $w_{20}^{(3)}=5.09 \mathrm{~mm}$ for the 10 - and 15 -mm-thick specimens. The average crack width also depends on the specimen size-it is larger for specimens with a smaller nominal area.

Finally, it is well known that there are only three types of regular polygons (triangles, squares, or hexagons) that can produce a regular tessellation in the Euclidean plane (Grünbaum and Shephard 1977, 1987). For all of them, the relation in the $\log -\log$ space of Fig. 21 between the area of a cell $(A)$ and the length of the crack per unit area $\left(\ell_{C}\right)$ has the linear form $\log A=B-2 \log \ell_{C}$ (Corte and Higashi 1960), where $B$ is a term that depends on the polygon type. This relation is independent of the size of the cells. Fig. 21 illustrates that the experiments performed in the present work are in acceptable accordance with this linear relation for a uniform tessellation and with other tests found in the literature (Ávila 2004; Corte and Higashi 1960). 
FIG. 20

Moisture loss and crack density factor with time for specimens AO-A4.

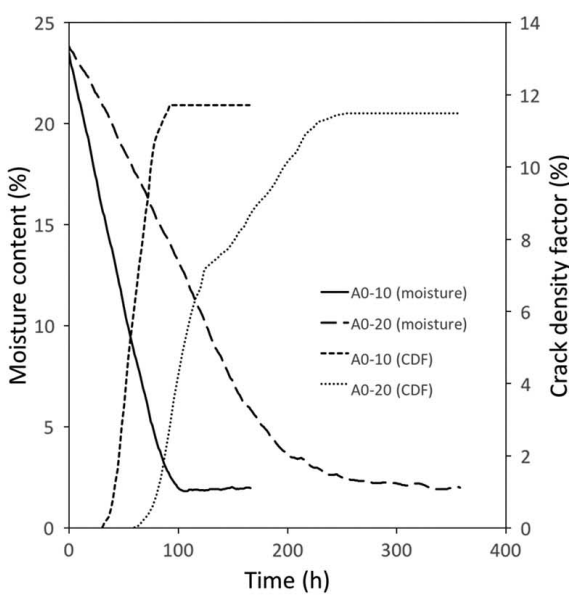

(a)

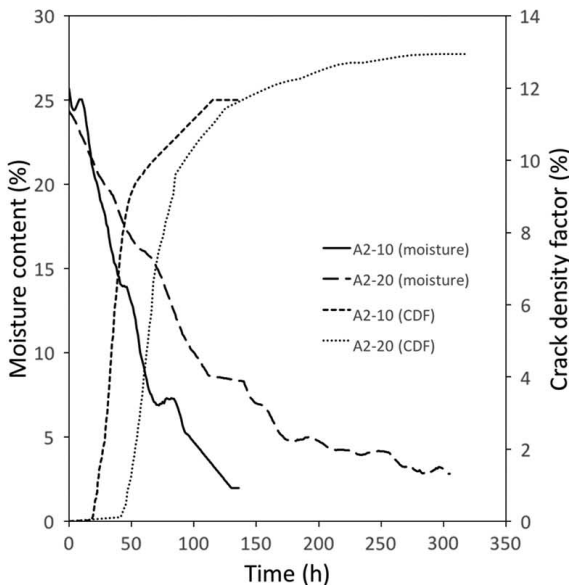

(c)

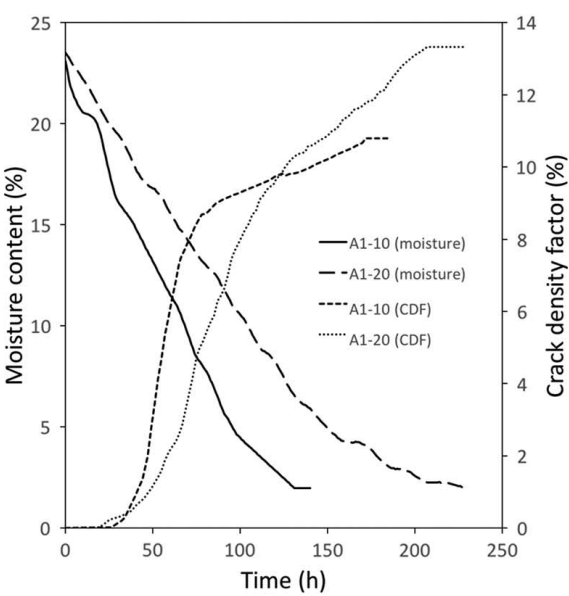

(b)

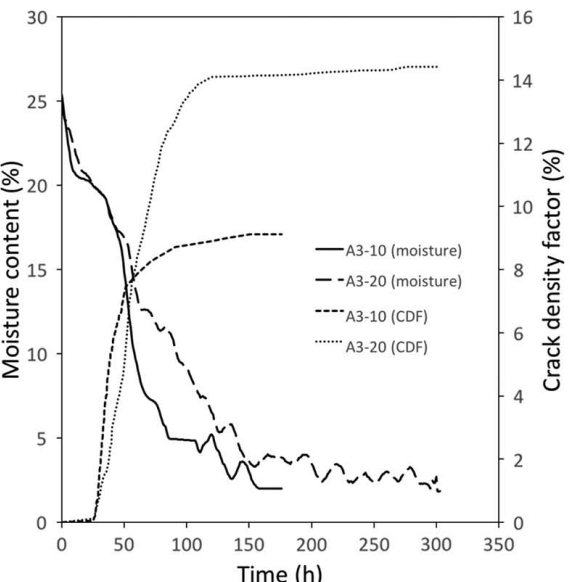

(d)

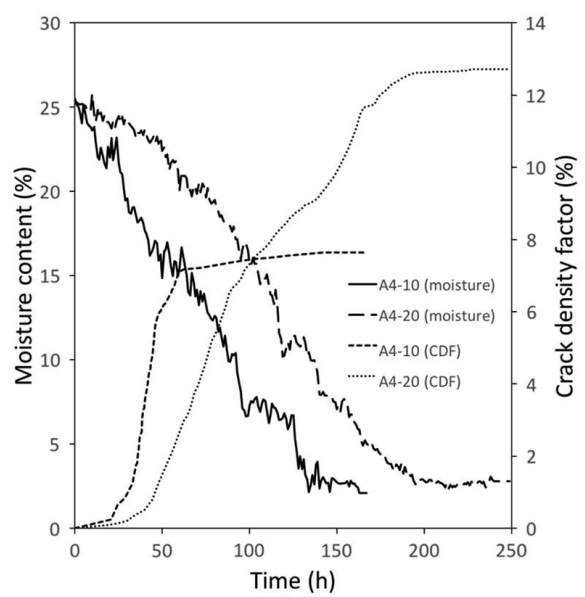

(e)

\section{SEQUENTIALITY OF CRACK FORMATION}

A large variety of morphologies of crack patterns can be found in nature. In many cases, the cracks or joints form a closed network and divide a two-dimensional surface into distinct domains. Very different mathematical, physical, biological, or social processes give rise to two-dimensional space-dividing patterns. Examples include the Voronoi tessellation of randomly distributed points (Aurenhammer, Klein, and Lee 2013; Voronoi 1908), the twodimensional soap froth confined between glass plates, the reticulum formed by cracks in thin layers, the cellular structure of two-dimensional living tissue, the leaf ventilation, or the division of large geographical areas by roads, streets, or political borders. 
FIG. 21 Relation between length of cracks and average area of cracked cells.

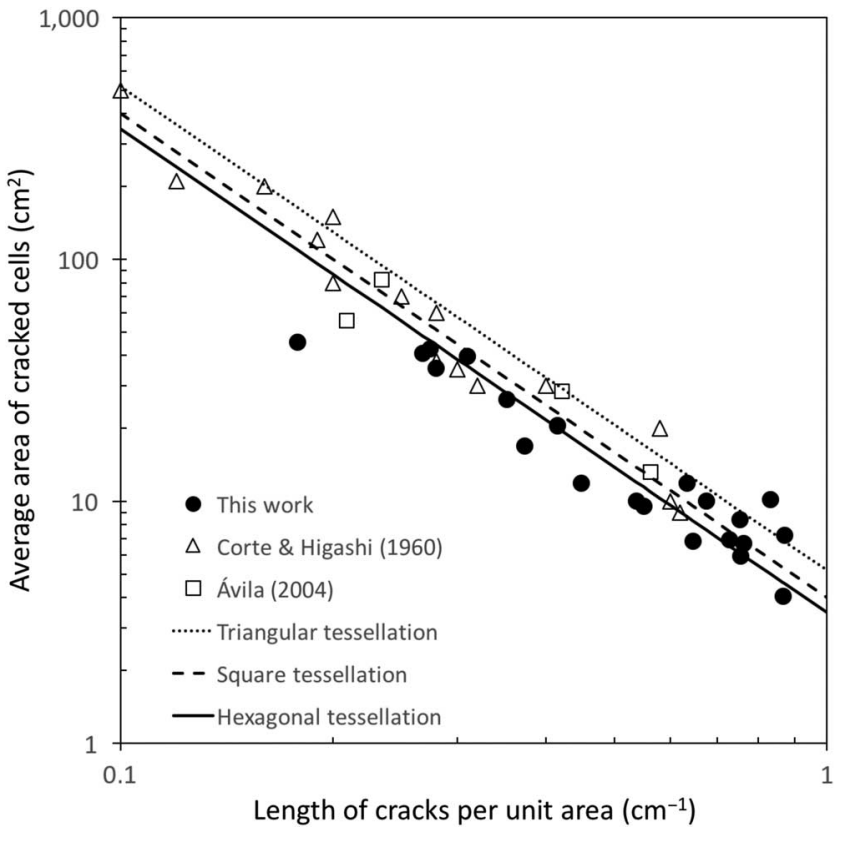

These networks have a well-known common property expressed by Euler's theorem, which states that in the plane each domain has, on average, six neighbors. For many cellular networks, it follows that the average number of sides per cell is also six.

The existence of a sequence in the crack formation was first reported from experimental studies in desiccating latex gels (Bohn 2005) and starch-water mixtures (Bohn, Pauchard, and Couder 2005; Bohn et al. 2005). However, no attempt has been made until recently (Costa, Kodikara, and Shannon 2013; Lakshmikantha, Prat, and Ledesma 2013) to study experimentally the existence of such a sequence in the cracking of soils.

Identification of the cracking sequence requires continuous time images of the evolving crack pattern as the soil dries, as was routinely carried out during the present investigation. For simplicity, only the A0-20 specimen is discussed, although the same process was observed in all specimens tested. The final crack pattern is shown in Fig. 22a, where the shaded cells are the ones in which the cracking sequence is being monitored. The time evolution of these cells is shown in the remaining images of Fig. 22b-i, which illustrate the process of successive crack formation that divides the surface into cells. The first image (Fig. 22b), taken 99 hours after the test started, shows a crack initiating nearly at the center of the cell. In the second image (Fig. 22c), taken at 103 hours, the crack in the earlier image has fully grown and is already reaching the cell's boundary cracks. It is interesting to notice that the crack divides the cell in half and that there are no other cracks anywhere else inside the cell. This newly formed crack intersects the cell's boundary cracks at right angles and is
FIG. 22 Temporal evolution of the crack formation, indicating its successive sequential nature: (a) final crack pattern corresponding to a section of the 20 -mm-thick $\mathrm{AO}$ specimen; (b) crack pattern at 99 hours; (c) crack pattern at 103 hours; (d) crack pattern at 107 hours; (e) crack pattern at 111 hours; (f) crack pattern at 115 hours; (g) crack pattern at 119 hours; (h) crack pattern at 131 hours; (i) crack pattern at 135 hours.

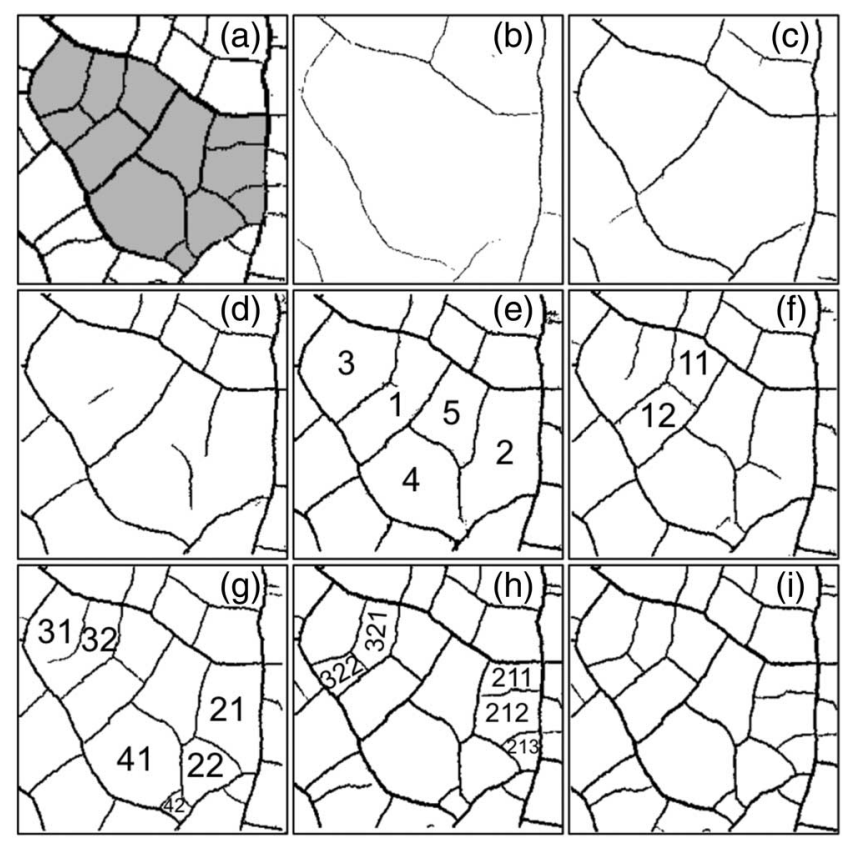

more or less perpendicular to the longest boundary cracks. From this point, crack formation within the two newly formed cells will proceed separately without influencing each other.

Focusing now on the bottom half-cell at the third image (Fig. 22d), taken at 107 hours, two cracks can be seen dividing the cell into three more subdomains, which can be seen fully formed in the fourth image (Fig. 22e), taken at 111 hours, labeled 2,4 , and 5 , respectively. At the same time, the top half-cell is split by a crack into two new cells, labeled 1 and 3 . Further, a new secondary crack can be seen at 115 hours in Fig. $22 \mathrm{f}$ at the middle of cell number 1, resulting in two new subcells, labeled 11 and 12 . At 119 hours, Fig. 22g shows that cells 2, 3, and 4 have also split by secondary cracks into two cells each, $21 / 22,31 / 32$, and $41 / 42$, respectively. Finally, the image shown in Fig. 22h, taken at 131 hours, shows a split of cells 21 and 32 by tertiary cracks into the new cells $211 / 212 / 213$ and $321 / 322$, respectively. There is no significant change between the latter image and the image (Fig. 22i) taken at 135 hours, which is almost identical to the final crack pattern shown in Fig. 22a, indicating that no more cracking occurred in this section of the specimen after that time.

Sequential cracking is a recurrent and natural phenomenon in drying soils where the cracks form and evolve driven by changes in material strength because of natural heterogeneities, or because of cycles of stress increases and decreases following seasonal 
environmental changes (Costa, Kodikara, and Shannon 2013). Usually sequential cracking results in patterns that are semidynamic or quasistatic when considered in a relative frame of elapsed time from their formation. For example, the domains formed by soap bubbles usually attain equilibrium in a very short time and are dynamic, constantly redistributing or repositioning themselves to maintain the equilibrium, leading to near-hexagonal patterns. In contrast, crack patterns formed in drying soils attain equilibrium relatively slowly depending on the rate of desiccation. This crack formation is not dynamic because there is no rearrangement of the domain shape and, normally, the size of the domains remain fixed in time, leading to near-orthogonal patterns.

Three important processes can explain the sequential nature of cracking in soils: (1) stress generation that is larger than the tensile strength; (2) the direction of the stress generation; and (3) the stress redistribution in the vicinity of or inside the newly formed domain. If the drying soil mass is sufficiently large, all three processes can occur simultaneously in different subdivided domains. Several factors are responsible for stress generation in a drying soil. First, soils are not continuous, homogeneous, or isotropic materials, and their granular nature is the main cause for stress generation. Also, soils are usually two- or three-phase systems with pore fluid and gas being the main constituents of the complex pore system in the soil matrix. Because of these factors, weak points or points of possible crack nucleation exist in the soil structure. These points are randomly distributed throughout the soil matrix, and the strength at these points varies depending upon the time evolution of cracking. The crack nucleation process itself also has a random component. In drying soils, stress generation is primarily caused by desiccation and a resistance to free shrinkage. Usually the shrinkage is not uniform over the drying surface, and this differential shrinkage results in differential stress generation at different points. The stresses at certain points may reach the soil strength earlier than at others, resulting in crack nucleation wherever the strength has been reached. Thereafter, cracks grow according to the direction of the principal stresses.

\section{Conclusions}

The results of the experiments have shown the coupling between specimen thickness, desiccation rate, and cracking moisture content in the formation and propagation of cracks. The main parameters that control cracking are the size, thickness, and aspect ratio of the specimen, and especially the boundary conditions (shape of the boundary and type of the soil-boundary interface). The surface area of the specimen and its thickness both affect the desiccation rate but in opposite ways: a larger area results in a higher desiccation rate, while a larger thickness results in a smaller desiccation rate.

Crack initiation happens when the specimen is saturated or near saturation. If a significant volume change occurs and there are displacement restrictions (because of the geometry and boundary conditions or because of material inhomogeneities), the deformation field ceases to be homogeneous and eventually cracking develops when a failure condition is satisfied.

The tests in the environmental chamber have shown that cracks can start either at the top, bottom, or at both surfaces of the specimen and that cracks can propagate with inclined paths along the vertical cross section. Cracks can also initiate within the soil mass, instead of at the surface of the specimen. The mechanism responsible for the initiation at the top surface is usually desiccation, while the cracks starting at the bottom surface may be a product of curling or syneresis processes or both.

The presence of a crack also affects the suction because cracks increase the rate of desiccation. The suction profiles during the initial stages of the desiccation showed that the drying front moves from the periphery toward the center and from top to bottom. The extent of cracking throughout the specimen was larger with a smooth bottom interface than with a rough one. This was more noticeable at the bottom surface.

The image analyses conducted on all tests clearly showed that the formation of cracks in drying soils is sequential. The cracking sequence provides much information that helps explain the way in which crack patterns are formed. Stepping back from the final crack pattern, knowledge of the sequential order makes it possible to trace the changing stress states during the process of cracking.

The role of specimen size and boundary (shape, interface) suggests the need for tests with larger specimens, with carefully designed soil-boundary interfaces, and with improved measurements, especially at the specimen-atmosphere interface where evaporation takes place. These tests would be fundamental for developing models that are able to predict the formation and propagation of cracks in natural soils under drying conditions, having useful applications in agriculture, water management, waste disposal, and construction in general.

\section{ACKNOWLEDGMENTS}

The financial support from research grants BIA2009-08341, awarded by the former Spanish Ministry of Science and Innovation, and BIA2012-36498, awarded by the Spanish Ministry of Economy and Competitiveness (both including FEDER funds, European Commission) is gratefully acknowledged.

\section{References}

Almhdie, A., Rozenbaum, O., Lespessailles, E., and Jennane, R., 2014, "Image Processing for the Non-Destructive Characterization of Porous Media. Application to Limestones and Trabecular Bones," Math. Comput. Simul., Vol. 99, pp. 82-94, https://doi.org/10.1016/j.matcom.2013.07.003

Asahina, D., Houseworth, J. E., Birkholzer, J. T., Rutqvist, J., and Bolander, J. E., 2014, "Hydro-Mechanical Model for Wetting/ 
Drying and Fracture Development in Geomaterials," Comput. Geosci., Vol. 65, pp. 13-23, https://doi.org/10.1016/j.cageo. 2013.12.009

Aurenhammer, F., Klein, R., and Lee, D.-T., 2013, Voronoi Diagrams and Delaunay Triangulations, World Scientific, Singapore, 348p.

Ávila, G., 2004, "Estudio de la Retracción y el Agrietamiento de Arcillas. Aplicación a la Arcilla de Bogotá," Ph.D. thesis, Polytechnic University of Catalonia-BarcelonaTech, Barcelona, Spain.

Ávila, G., Ledesma, A., and Lloret, A., 2013, “One-Dimensional Cracking Model in Clayey Soils," presented at the 18th International Conference on Soil Mechanics and Geotechnical Engineering, Paris, France, French Society for Soil Mechanics and Geotechnical Engineering, Rueil-Malmaison, France, pp. 1077-1080.

Ayad, R., Konrad, J.-M., and Soulié, M., 1997, "Desiccation of a Sensitive Clay: Application of the Model CRACK," Can. Geotech. J., Vol. 34, No. 6, pp. 943-951, https://doi.org/10. 1139/t97-065

Aydemir, S., Keskin, S., and Drees, L. R., 2004, "Quantification of Soil Features Using Digital Image Processing (DIP) Techniques," Geoderma, Vol. 119, Nos. 1-2, pp. 1-8, https:// doi.org/10.1016/S0016-7061(03)00218-0

Barrera, M., 2002, "Estudio Experimental del Comportamiento Hidro-Mecánico de Suelos Colapsables," Ph.D. thesis, Polytechnic Univerisity of Catalonia-BarcelonaTech, Barcelona, Spain.

Bažant, Z. P., 1984, "Size Effect in Blunt Fracture: Concrete, Rock, Metal,” J. Eng. Mech., Vol. 110, No. 4, pp. 518-535, https://doi. org/10.1061/(ASCE)0733-9399(1984)110:4(518)

Bohn, S., 2005, "Hierarchical Crack Patterns: A Comparison with Two-Dimensional Soap Foams," Colloids Surf., A, Vol. 263, Nos. 1-3, pp. 46-51, https://doi.org/10.1016/j.colsurfa.2004.11.013

Bohn, S., Pauchard, L., and Couder, Y., 2005, "Hierarchical Crack Pattern as Formed by Successive Domain Divisions. I. Temporal and Geometrical Hierarchy," Phys. Rev. E: Stat. Nonlinear Soft Matter Phys., Vol. 71, No. 046124, pp. 1-7.

Bohn, S., Platkiewicz, J., Andreotti, B., Adda-Bedia, M., and Couder, Y., 2005, "Hierarchical Crack Pattern as Formed by Successive Domain Divisions. II. From Disordered to Deterministic Behavior," Phys. Rev. E: Stat. Nonlinear Soft Matter Phys., Vol. 71, No. 046215, pp. 1-7.

Chertkov, V. Y., 2002, "Characteristic Crack Dimension of Saturated Drying Soils: Theory and Applications," Agric. Eng. Int.: CIGR J. Sci. Res. Dev., Manuscript LW 02 001, Vol. 4.

Chertkov, V. Y. and Ravina, I., 1999, “Tortuosity of Crack Networks in Swelling Clay Soils," Soil Sci. Soc. Am. J., Vol. 63, No. 6, pp. 1523-1530, https://doi.org/10.2136/sssaj1999.6361523x

Cordero, J., Cuadrado, A., Ledesma, A., and Prat, P. C., 2014, "Patterns of Cracking in Soils Due to Drying and Wetting Cycles," presented at the Sixth International Conference on Unsaturated Soils, UNSAT 2014, Sydney, Australia, Taylor and Francis, Abingdon, United Kingdom, pp. 381-387.

Cordero, J., Prat, P. C., Ledesma, A., and Cuadrado, A., 2015, "Cracking Behaviour of Silty Clay Soil under DryingWetting Cycles," Shrink-Swell Processes in Soils - Climate and Construction, J.-P. Magnan, Ed., Marne-la-Vallée, France, June 18-19, The French Institute of Science and Technology for Transport, Development and Networks, Marne-la-Vallée, France, pp. 81-90.
Corte, A. E. and Higashi, A., 1960, "Experimental Research on Desiccation Cracks in Soil, Report No. 66," US Army Snow, Ice, and Permafrost Research Establishment, Corps of Engineers, Wilmette, IL, USA, pp. 1-48.

Costa, S., Kodikara, J., and Shannon, B., 2013, "Salient Factors Controlling Desiccation Cracking of Clay in Laboratory Experiments," Géotechnique, Vol. 63, No. 1, pp. 18-29, https:// doi.org/10.1680/geot.9.P.105

Goehring, L., Nakahara, A., Dutta, T., Kitsunezaki, S., and Tarafdar, S., 2015, Dessication Cracks and Their Patterns. Formation and Modelling in Science and Nature, Wiley-VCH, Weinheim, Germany, 368p.

Groisman, A. and Kaplan, E., 1994, "An Experimental Study of Cracking Induced by Desiccation," Europhys. Lett., Vol. 25, No. 6, pp. 415-420, https://doi.org/10.1209/0295-5075/25/ $6 / 004$

Grünbaum, B. and Shephard, G. C., 1977, "Tilings by Regular Polygons," Math. Mag., Vol. 50, No. 5, pp. 227-247, https://doi.org/10.2307/2689529

Grünbaum, B. and Shephard, G. C., 1987, Tilings and Patterns, Spektrum Akademischer Verlag, Berlin, Germany, 700p.

Hartge, K. H. and Bachmann, J., 2000, “Angles between Cracks Developed at Primary Shrinkage of Fine-Grained Soil Material," Int. Agrophys., Vol. 14, No. 1, pp. 43-51.

Kodikara, J., Barbour, S. L., and Fredlund, D. G., 2000, "Desiccation Cracking of Soil Layers," Unsaturated Soils for Asia, H. Raharjdo Ed., CRC Press, Boca Raton, FL, pp. 693-698.

Lakshmikantha, M. R., 2009, "Experimental and Theoretical Analysis of in Drying Soils," Ph.D. thesis, Polytechnic University of Catalonia-BarcelonaTech, Barcelona, Spain.

Lakshmikantha, M. R., Prat, P. C., and Ledesma, A., 2009, "Image Analysis for the Quantification of a Developing Crack Network on a Drying Soil," Geotech. Test. J., Vol. 32, No. 6, pp. 505-515, https://doi.org/10.1520/GTJ102216

Lakshmikantha, M. R., Prat, P. C., and Ledesma, A., 2012, "Experimental Evidences of Size-Effect in Soil Cracking," Can. Geotech. J., Vol. 49, No. 3, pp. 264-284, https://doi. org/10.1139/t11-102

Lakshmikantha, M. R., Prat, P. C., and Ledesma, A., 2013, "Evidences of Hierarchy in Cracking of Drying Soils," presented at Geo-Congress 2013, San Diego, CA, 2013, American Society of Civil Engineers, Reston, VA, pp. 782-789.

Levatti, H. U., 2015, "Estudio Experimental y Análisis Numérico de la Desecación en Suelos Arcillosos," Ph.D. thesis, Polytechnic University of Catalonia-BarcelonaTech, Barcelona, Spain.

Levatti, H. U., Prat, P. C., Ledesma, A., Cuadrado, A., and Cordero, J. A., 2017, "Experimental Analysis of 3D Cracking in Drying Soils Using Ground Penetrating Radar," Geotech. Test. J., Vol. 40, No. 2, pp. 221-243, https://doi. org/10.1520/GTJ20160066

Liu, C., Shi, B., Zhou, J., and Tang, C.-S., 2011, "Quantification and Characterization of Microporosity by Image Processing, Geometric Measurement and Statistical Methods: Application on SEM Images of Clay Materials," Appl. Clay Sci., Vol. 54, No. 1, pp. 97-106, https://doi.org/10.1016/j. clay.2011.07.022

Liu, C., Tang, C.-S., Shi, B., and Suo, W.-B., 2013, "Automatic Quantification of Crack Patterns by Image Processing," 
Comput. Geosci., Vol. 57, pp. 77-80, https://doi.org/10.1016/j. cageo.2013.04.008

Lloret, A., Ledesma, A., Rodríguez, R. L., Sánchez, M. J., Olivella, S., and Suriol, J., 1998, "Crack Initiation in Drying Soils," presented at the Second International Conference on Unsaturated Soils, Beijing, China, International Academic Publishers, Beijing, China, pp. 497-502.

Lu, N. and Kaya, M., 2013, "A Drying Cake Method for Measuring Suction-Stress Characteristic Curve, Soil-WaterRetention Curve, and Hydraulic Conductivity Function," Geotech. Test. J., Vol. 36, No. 1, pp. 1-19, https://doi.org/ 10.1520/GTJ20120097

Miller, C. J., Mi, H., and Yesiller, N., 1998, "Experimental Analysis of Desiccation Crack Propagation in Clay Liners," J. Am. Water Resour. Assoc., Vol. 34, No. 3, pp. 677-686, https:// doi.org/10.1111/j.1752-1688.1998.tb00964.x

Miller, E. E., 1975, "Physics of Swelling and Cracking Soils," J. Colloid Interface Sci., Vol. 52, No. 3, pp. 434-443, https:// doi.org/10.1016/0021-9797(75)90268-4

Morris, P. H., Graham, J., and Williams, D. J., 1992, "Cracking in Drying Soils,” Can. Geotech. J., Vol. 29, No. 2, pp. 263-277, https://doi.org/10.1139/t92-030

Nahlawi, H. and Kodikara, J. K., 2006, "Laboratory Experiments on Desiccation Cracking of Thin Soil Layers," Geotech. Geol. Eng., Vol. 24, No. 6, pp. 1641-1664, https://doi.org/10.1007/ s10706-005-4894-4

Peng, X., Horn, R., Peth, S., and Smucker, A., 2006, "Quantification of Soil Shrinkage in 2D by Digital Image Processing of Soil Surface," Soil Tillage Res., Vol. 91, Nos. 1-2, pp. 173-180, https://doi.org/10.1016/j.still.2005.12.012

Péron, H., 2008, "Desiccation Cracking of Soils," Ph.D. thesis, École Polytechnique Federal de Lausanne, Lausanne, Switzerland.

Péron, H., Hueckel, T., Laloui, L., and Hu, L. B., 2009, "Fundamentals of Desiccation Cracking of Fine-Grained Soils: Experimental Characterisation and Mechanisms
Identification," Can. Geotech. J., Vol. 46, No. 10, pp. 1177-1201, https://doi.org/10.1139/T09-054

Plummer, P. S. and Gostin, V. A., 1981, "Shrinkage Cracks; Desiccation or Synaeresis?,” J. Sediment. Res., Vol. 51, No. 4, pp. 1147-1156.

Pratt, B. R., 1998, "Syneresis Cracks: Subaqueous Shrinkage in Argillaceous Sediments Caused by Earthquake-Induced Dewatering," Sediment. Geol., Vol. 117, Nos. 1-2, pp. 1-10, https://doi.org/10.1016/S0037-0738(98)00023-2

Rodríguez, R. L., 2006, "Hydrogeotechnical Characterization of a Metallurgical Waste," Can. Geotech. J., Vol. 43, No. 10, pp. 1042-1060, https://doi.org/10.1139/t06-061

Rodríguez, R. L., Sánchez, M. J., Ledesma, A., and Lloret, A., 2007, "Experimental and Numerical Analysis of a Mining Waste Desiccation," Can. Geotech. J., Vol. 44, No. 6, pp. 644-658, https://doi.org/10.1139/t07-016

Sánchez, M., Manzoli, O. L., and Guimarães, L. J. N., 2014, "Modeling 3-D Desiccation Soil Crack Networks Using a Mesh Fragmentation Technique," Comput. Geotech., Vol. 62, pp. 27-39, https://doi.org/10.1016/j.compgeo.2014.06.009

Shin, H. and Santamarina, J. C., 2011, "Open-Mode Discontinuities in Soils," Géotechnique Lett., Vol. 1, No. 4, pp. 95-99, https://doi.org/10.1680/geolett.11.00014

Shit, P. K., Bhunia, G. S., and Maiti, R., 2015, "Soil Crack Morphology Analysis Using Image Processing Techniques," Model. Earth Syst. Environ., Vol. 1, No. 35, pp. 1-7.

Tang, C.-S., Shi, B., Liu, C., Gao, L., and Inyang, H. I., 2011, "Experimental Investigation of the Desiccation Cracking Behavior of Soil Layers during Drying," J. Mater. Civil Eng., Vol. 23, No. 6, pp. 873-878, https://doi.org/10.1061/(ASCE) MT.1943-5533.0000242

Voronoi, G., 1908, "Nouvelles Applications des Paramètres Continus à la Théorie des Formes Quadratiques," Journal für die Reine und Angewandte Mathematik, Vol. 133, pp. 97-178, https://doi.org/10.1515/crll.1908.134.198 